\title{
Supercritical CO2-Assisted Atomization for Deposition of Cellulose Nanocrystals: An Experimental and Computational Study
}

\section{Shadi Shariatnia}

Texas A\&M University College Station: Texas A\&M University

\section{Prajesh Jangale}

Texas A\&M University College Station: Texas A\&M University

\section{Rohit Mishra}

Texas A\&M University College Station: Texas A\&M University

\section{Amir Asadi}

Texas A\&M University College Station: Texas A\&M University

\section{Dorrin Jarrahbashi ( $\nabla$ djarrahbashi@tamu.edu )}

Texas A and M University: Texas A\&M University

\section{Research Article}

Keywords: Nanoparticle Spray Deposition, Supercritical-Assisted Atomization, Evaporation Induced Nanostructure Fabrication, Cellulose Nanocrystals

Posted Date: August 13th, 2021

DOI: https://doi.org/10.21203/rs.3.rs-758403/v1

License: (c) (1) This work is licensed under a Creative Commons Attribution 4.0 International License. Read Full License

Version of Record: A version of this preprint was published at Cellulose on January 21st, 2022. See the published version at https://doi.org/10.1007/s10570-021-04368-7. 
Supercritical CO2-Assisted Atomization for Deposition of Cellulose Nanocrystals: An Experimental and Computational Study

\author{
Shadi Shariatnia ${ }^{\text {a }}$, Prajesh Jangale ${ }^{\text {a }}$, Rohit Mishra ${ }^{\text {a }}$, Amir Asadi ${ }^{\mathrm{a}, \mathrm{b}}$, Dorrin Jarrahbashi ${ }^{\mathrm{a}^{*}}$ \\ a J. Mike Walker '66 Department of Mechanical Engineering - Texas A\&M University, \\ College Station, TX 77843, United States \\ ${ }^{\mathrm{b}}$ Manufacturing and Mechanical Engineering Technology - Department of Engineering \\ Technology and Industrial Distribution - Texas A\&M University, College Station, TX 77843, \\ United States
}


Abstract

Nanoparticle spray deposition finds numerous applications in pharmaceutical, electronics, manufacturing, and energy industries and has shown great promises in engineering the functional properties of the coated parts. However, current spray deposition systems either lack the required precision in controlling the morphology of the deposited nanostructures or do not have the capacity for large-scale deposition applications. In this study, we introduce a novel spray system that uses supercritical $\mathrm{CO}_{2}$ to assist the atomization process and create uniform micron-size water droplets that are used as cellulose nanocrystal (CNC) carriers. CNCs are selected in this study as they are abundant, possess superior mechanical properties, and contain hydroxyl groups that facilitate interaction with neighboring materials. We fundamentally investigate the effect of different process parameters, such as injection pressure, gas-to-liquid ratio, the axial distance between the nozzle and substrate, and $\mathrm{CNC}$ concentration on the final patterns left on the substrate upon evaporation of water droplets. To this end, we show how tuning process parameters control the size of carrier droplets, dynamics of evaporation, and self-assembly of CNCs, which in turn dictate the final architecture of the deposited nanostructures. We will particularly investigate the morphology of the nanostructures deposited after evaporation of micron-size droplets that has not been fully disclosed to date. Different characterization techniques such as laser diffraction, polarized microscopy, and high-resolution profilometry are employed to visualize and quantify the effect of each process parameter. Numerical simulations are employed to inform the design of experiments. Finally, it is shown that the fabricated nanostructures can be engineered based on the size of the carrier droplets controlled by adjusting spray parameters and the concentration of nanoparticles in the injected mixture. Process parameters can be selected such that nanoparticles form a ring, disk, or dome-shaped structure. Moderate operational conditions, simplicity and time efficiency of the process, and use of abundant and biodegradable materials, i.e., water, CNC, and $\mathrm{CO}_{2}$ promote the scalability and sustainability of this method.

76

77

78

79

Keywords

80 Nanoparticle Spray Deposition, Supercritical-Assisted Atomization, Evaporation Induced Nanostructure 81 Fabrication, Cellulose Nanocrystals

82 


\section{Introduction}

84 Deposition of nanoparticles via liquid atomization finds several practical applications in food, ${ }^{1-3}$ drug delivery, ${ }^{4,5}$ manufacturing, ${ }^{6,7}$ energy, ${ }^{8-10}$ electronics, ${ }^{11,12}$ and surface coating. ${ }^{13}$ Liquid atomization is referred to as a hydrodynamic process through which a liquid jet injected via a small nozzle breaks up into several micron-size and submicron droplets upon exposure to the surrounding fluid and forms a spray. Spray deposition is a simple one-step, safe and low-cost method for coating large surface areas within few seconds to promote the efficiency and scalability, while reducing materials usage. In the nanoparticle spray deposition process, a colloidal suspension is atomized to create droplets containing nanoparticles of interest that subsequently evaporate and leave the particles on the target surface.

Various configurations of thermal sprays, ${ }^{14-16}$ electrical sprays, ${ }^{17,} 18$ and direct-write deposition ${ }^{19-22}$ are among the most common spray deposition methods that have been extensively studied. Thermal spray systems such as warm, ${ }^{23,24}$ plasma, ${ }^{25-27}$ and electro sprays ${ }^{28,29}$ use a heat source, either through a chemical reaction, plasma discharge, or electricity to melt the feedstock material and spray it on a substrate using a high-speed jet. Cold spray systems where solid powders (rather than a melted material) are accelerated in a de Laval nozzle towards the substrate, fall under the thermal spray category. ${ }^{15}$ Due to the harsh conditions in these sprays, coatings and substrates are limited to materials that can withstand large impact forces and are compatible with high temperature (and/or temperature gradients). ${ }^{30}$ Metals and metallic alloys, ceramics, glasses, polymers, and plastics are commonly used as the coating material in such systems. ${ }^{15}$ These coatings are often utilized to prevent chemical and mechanical damage to different structures depending on the functionality of the part. ${ }^{31}$ Thermal sprays are cost effective and can cover large surface areas in a short period of time with a thickness that can range from $~ 20$ microns to several millimeters. ${ }^{32}$ However, thermal methods lack the precision needed for coatings layers with a few nanometer thicknesses, and they do not provide any control over the formation and final morphology of the deposited nanostructures. ${ }^{29}$

Direct-write deposition techniques on the other hand, e.g. inkjet and aerosol jet printing, precisely control the deposition of colloidal droplets and formation of nanostructures on a targeted location. ${ }^{19,33}$ These methods find numerous applications in electronics ${ }^{34-40}$ and life sciences, ${ }^{41-43}$ with a plethora of research focused on developing customized inks for printing different materials. ${ }^{44-47}$ Upon deposition on the substrate, the contact line of the ink droplets pins to the substrate. As the droplet evaporation proceeds, the contact angle between the droplet and substrate decreases. As a result, a capillary flow from the center of the droplet towards the pinned contact line initiates to compensate the liquid mass loss at the droplet's periphery. ${ }^{48}$ This flow drags the particles and accumulates them along the edge of the droplet leaving a ring-shaped trace of particles on the substrate. ${ }^{49}$ This phenomenon is known as the coffee ring effect (CRE) that can be exploited or suppressed to enforce a specific nanoparticle pattern on the substrate depending on the application. ${ }^{48}$ Suppression of the CRE in direct writing methods requires costly and multi-step processes such as the use of flammable, toxic, and hazardous surfactants to the solvent, ${ }^{50-52}$ physical and chemical 
${ }^{55-57}$ Inkjet printing is limited to deposition of a single or a few droplets at a time that covers a small surface area limiting the scalability of this technique. In addition, since the process parameters are set prior to print, achieving thickness and material variability, requires multiple rounds of deposition or using multiple print heads. ${ }^{58,59}$

There are also several high-throughput spray-based techniques to create and release nanoparticles through atomization of colloidal solutions, such as spray pyrolysis ${ }^{60}$ and spray drying ${ }^{61}$ widely used in pharmaceutical and food industries. ${ }^{62-64}$ Their adoption is owed to the compatibility of these techniques with a large variety of materials. In our previous study, the superiority of spray deposition of cellulose nanocrystals over other conventional coating methods (i.e., dip-coating) was fully studied. ${ }^{65}$ However, due to the inherent uncertainties, randomness, and wide size distribution of droplets created by atomization, these systems lack the precision and control over the formation and homogeneity of the produced nanoparticles. ${ }^{66}$ Aerosol jet printing utilizes an air-assisted atomization technique for breakup of the liquid jet stream and a specific directed nozzle to facilitate targeted deposition. ${ }^{67}$ This technique is faster than inkjet printing and is compatible for deposition on any substrate and capable of handling a wide range of materials in moderate operating conditions (i.e., low temperatures and pressures). ${ }^{12,68}$ It also provides precise control over the thickness and profile of the material deposition with the first round of spray. ${ }^{69,70}$ However, aerosol jet printing lacks the capability of large-scale printing/deposition. ${ }^{71,72}$ The internal design of the nozzle that directly affects the quality and dimensional resolution of the print is very complicated and is not suitable for printing single dots or square-shaped geometries. ${ }^{59,73}$ Other limitations of this method include low solubility of particles in the solvent and lack of control over droplet sizes. ${ }^{74,75}$

To overcome these limitations, supercritical-assisted atomization (SAA) has been introduced as a method that utilizes a fluid above its thermodynamic critical point to facilitate the atomization process by enhancing the nanoparticles dissolution in solvents. ${ }^{76}$ SAA accelerates liquid atomization by exploiting the hybrid gas-like and liquid-like properties of supercritical fluids. High density and high diffusivity along with low viscosity of supercritical fluids enhances the dissolution of gasses into the injected mixture (comprised of the solvent and nanoparticles) and reduces the surface tension between the injected liquid and the surrounding gas that both contribute to an improved atomization process and spray formation. ${ }^{77,78}$ Owing to their high diffusivity, supercritical fluids highly dissolve in the liquid mixture prior to injection and separate from the mixture in the form of gas bubbles upon injection into the surrounding environment. The sudden expansion of these gas bubbles, triggers the breakup of the liquid jet and shatters it into very fine and highly uniform droplets with a narrow size distribution compared to other spray-based techniques. ${ }^{79}$ Material selection is an important factor in designing the SAA system, especially in micronization and powder manufacturing applications where solid particles that are dissolved in the supercritical mixture need to preserve their properties after dissolution. $\mathrm{CO}_{2}$ is an abundant, degradable, nontoxic, and nonflammable gas with moderate critical temperature and pressure $\left(31^{\circ} \mathrm{C}\right.$ and $\left.7.4 \mathrm{MPa}\right)$ compared to other fluids, which makes it a viable option for several applications such as temperature-sensitive materials used in pharmaceutical and biological 
applications. ${ }^{80,81}$ The high solubility of supercritical $\mathrm{CO}_{2}\left(\mathrm{SCO}_{2}\right)$ in most organic and inorganic solvents has made it the supercritical fluid of choice in SAA systems. ${ }^{82,83}$ Sensitivity of mixture properties to the operational conditions enables the regulation of droplet sizes and the final morphology of the fabricated particles. ${ }^{84}$ Although SAA provides great control over process parameters, it is limited to solely manufacturing micro/nanoparticles that are collected in a precipitator in the form of dry powder after atomization.

An important application of SAA is the direct deposition of nanoparticle-carrier droplets resulting from atomization of nano-colloidal suspensions exposed to $\mathrm{SCO}_{2}$ and exploiting that process to engineer the nanostructures on a substrate. However, due to complex underlying atomization mechanisms in SAA, this potentially important application has not been fully explored in the literature to date. This knowledge gap motivated the current study where we have designed and built a novel SAA system to atomize aqueous Cellulose nanocrystal (CNCs) suspension and deposit the droplets containing $\mathrm{CNC}$ on a solid substrate to fabricate nanostructures with controlled size and morphology. In our previous study, we experimentally studied the effect of a wide range of process parameters such as GLR, injection pressure, and axial distance from the injection orifice on the breakup and final droplet size in the absence of nanoparticles ${ }^{85}$. In this study, we utilize SAA as a new large-scale delivery method for depositing CNCs and controlling the fabrication of nanostructures on solid substrates. The proposed spray deposition technique can seamlessly be adopted for several practical applications involving $\mathrm{CNCs}$ and other nanoparticles. The main objective of this study is to (1) understand the effect of spray parameters and colloidal suspension properties on the shape of the nanostructures formed on the substrate after droplet evaporation, and (2) use this knowledge to effectively control and tailor the architecture of deposited nanostructures.

We adopted CNC in this study as it forms a stable dispersion in water and possesses unique mechanical and chemical properties that make it appealing for a variety of applications, from 3D printing ${ }^{7}$ and manufacturing, ${ }^{86-88}$ to drug delivery ${ }^{89}$ and electronics. ${ }^{90} \mathrm{CNCs}$ with linear chain glucose units $\left(\mathrm{C}_{6} \mathrm{H}_{10} \mathrm{O}_{5}\right)$ are abundant, non-toxic, and biodegradable spindle-shaped nanoparticles obtained from plants, algae, bacteria, and marine animals. ${ }^{91,73} \mathrm{CNC}$ contains accessible hydroxyl groups on its surface that makes it suitable for chemical modification. ${ }^{92}$ In addition, CNCs possess unique features such as low density $\left(1.5 \mathrm{~g} / \mathrm{cm}^{3}\right)$, elastic modulus of $110-220 \mathrm{GPa}$, tensile strength of 3-7.5 GPa, high aspect ratio (10-100), and high surface area. ${ }^{92}$ Evaporation-induced selfassembly of aqueous CNC droplets has been widely studied for optical sensing, security labeling, food, cosmetics, textiles, and art applications. ${ }^{93-97}$ However, these studies are focused on investigating the patterns in a liquid film or a single droplet and involve time and cost-inefficient lab-scale processes. To this end, we experimentally investigate the effect of different spray parameters and the concentration of $\mathrm{CNC}$ on the mean droplet sizes and the morphology of the created nanostructure. We have leveraged computational fluid dynamics (CFD) simulations to obtain the optimum spray parameters, achieve the desired film thickness, and indicate the prime location for delivery of droplets on the substrate where minimum droplet evaporation and spray bounce-back occurs. The computational results inform the experimental system design, and thus 
reduce the trial-and-error process to obtain the optimum deposition outcome with minimum material waste and ensure system scalability.

The remainder of this paper is structured as follows: the spray deposition setup and materials selected for this work, as well as the characterization techniques, are described in Section 2. Governing equations and computational methods utilized in simulations are described in Section 3. Results and Discussion are presented in Section 4, where the effects of spray parameters on the final nanostructures assembled on the substrate are visualized and measured using microscopy and profilometry. The resulting film thickness and droplet behavior at different spray parameters from numerical simulations are also presented. The Conclusions presented in Section 5 concludes this

212 paper.

\section{2. Experimental Method}

\subsection{Spray Setup and Diagnostics}

Figure 1 shows a schematic of the experimental setup for SAA spray deposition of CNCs on a glass substrate. The spray system has two feed lines that deliver $\mathrm{CO}_{2}$ and the aqueous $\mathrm{CNC}$ suspension to a custom-made pressure vessel. The ternary mixture, i.e., $\mathrm{CNC}$, water, and $\mathrm{CO}_{2}$, mix and reside in the pressure vessel. A pump feeds the colloidal suspension into the pressure vessel, while another pump connects the $\mathrm{CO}_{2}$ tank to the pressure vessel. Pressure and temperature are monitored in multiple locations along the feeding lines and inside the vessel using several pressure gauges and thermometers. The mixture is then injected into the ambient atmospheric air towards a glass substrate (VWR, micro cover glass No. 1.5). The internal geometry of the nozzle is a straight, 223 circular cylinder with an actuator.

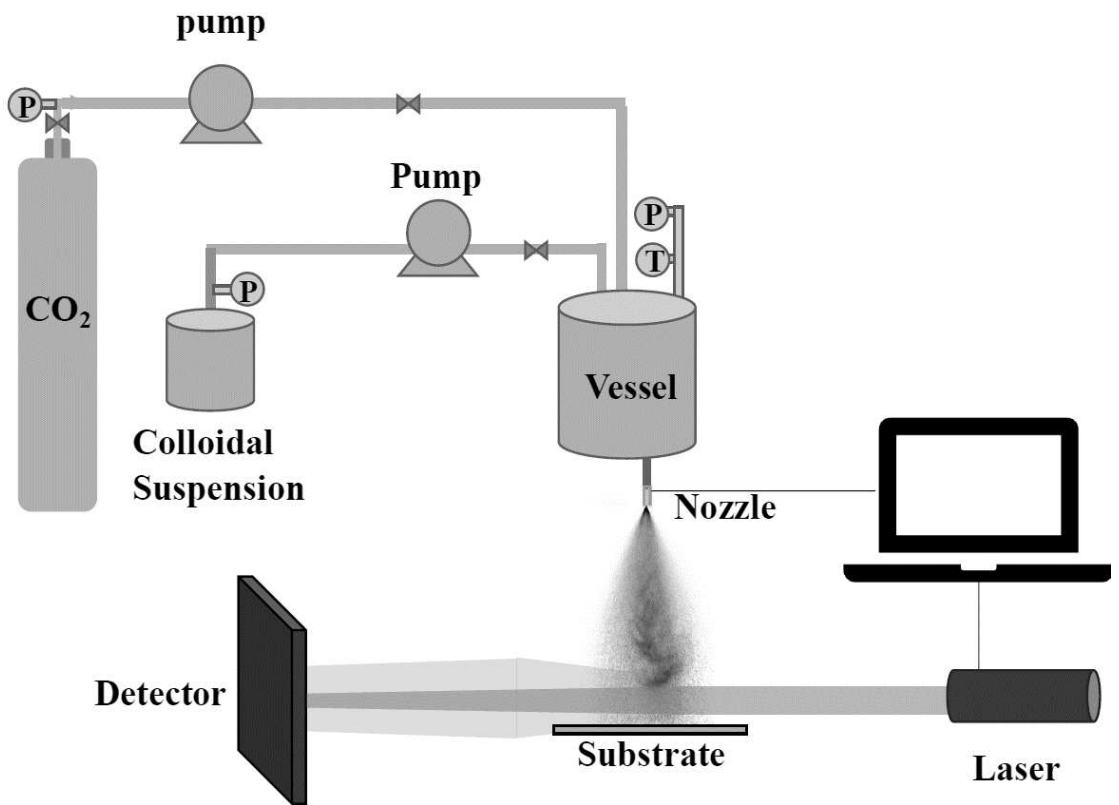

Figure 1. A schematic of the experimental setup indicating the feed gas tanks, pumps, pressure vessel, nozzle, substrate, and the laser diffraction system. 


\subsection{Materials}

CNCs with an average diameter and length of 3 and $75 \mathrm{~nm}$, respectively were provided by CelluForce (Quebec, Canada). CNC with concentration of 0.2, 0.5, $2 \mathrm{wt} \%$ were dispersed in 500 $\mathrm{mL}$ of deionized water $\left(\mathrm{DI}-\mathrm{H}_{2} \mathrm{O}\right)$ using probe sonication (Qsonica Q125 equipped with a $12 \mathrm{~mm}$ sonotrode) for $30 \mathrm{~min}$ at a frequency of $20 \mathrm{kHz}$ and $75 \%$ intensity. Sonication was performed at room temperature and the colloidal suspension was used within two hours to prevent sedimentation and ensure the quality of the dispersion.

\subsection{Test Conditions}

Table 1 represents different test cases and corresponding experimental conditions including the concentration of $\mathrm{CNC}$ in the injected suspension, injection pressure, and gas-to-liquid ratio (GLR). GLR is the ratio of the $\mathrm{CO}_{2}$ mass flow rate to the liquid (nanoparticle suspension) mass flow rate measured upon feeding $\mathrm{CO}_{2}$ and the liquid separately into the mixing chamber prior to injection. GLR is commonly used to represent the gas content in the injection mixture. The axial distance from the injection nozzle where droplet Sauter Mean Diameter (SMD) is measured is outlined in Table 1. The average size of droplets in a spray is commonly represented by Sauter

247 $D_{s}$, where the surface diameter and volume diameter are defined by $D_{s}=\sqrt{\frac{A}{\pi}}$, and $D_{v}=\left(\frac{6 V}{\pi}\right)^{\frac{1}{3}}$, respectively and $A$ and $V$ represent the surface area and volume of the droplet, respectively. All experiments were carried out at room conditions $\left(25^{\circ} \mathrm{C}\right.$ and relative humidity $\left.\sim 40 \%\right)$.

Table 1. Design of experiments

\begin{tabular}{|c|c|c|c|}
\hline CNC Concentration (wt\%) & Injection Pressure (MPa) & Axial Distance (cm) & GLR \\
\cline { 1 - 1 } 0.2 & \multirow{3}{*}{$3,6,7.5,9$} & & $0.02,0.05$, \\
\cline { 1 - 1 } 0.5 & & $10,15,20$ & $0.075,0.1$, \\
\cline { 1 - 1 } 2 & & & $0.2,0.5,1,2$, \\
& & & 3,4 \\
\hline
\end{tabular}

\subsection{Characterization Techniques}

253 2.3.1 Microscopy

254 A Leica DM6B (Leica Microsystems Inc., Germany) motorized microscope equipped with 2x$25540 x$ objectives is used to portray the distribution of droplets on the glass substrate. Polarized light 256 mode is applied to visualize the distribution of the crystalline CNCs that are otherwise transparent 257 to brightfield lighting.

258 2.3.2 High-Speed Imaging 
A Fastcam SA5 (CA, USA) high-speed camera equipped with a Nikon Nikkor (Tokyo, Japan) micro lens is used for diffuse back-illumination imaging of the spray development. The resolving power of this optical system correlated with the smallest feature that it can accurately capture is $\sim 20 \mu \mathrm{m}$. The images are captured with a frame rate of 500,000 fps and have a 128×64 pixels field of view.

\subsubsection{Laser Diffraction}

A Malvern Panalytical's laser diffraction system (Malvern, UK) with a He-Ne laser source is used for real-time measurements of the average volume-based droplet size (SMD) at different axial locations across the spray. Sampling errors and the back-end algorithms that are deployed in the system software to convert the scattered light into meaningful particle size measurements are the main limitations of these systems, ${ }^{98}$ yet the system has a $1 \mathrm{~Hz}$ acquisition rate, $0.1 \mu \mathrm{m}$ resolution, and $99 \%$ accuracy in size measurements. Measurements are captured from the diffraction pattern of the superimposed laser beam and the spray. All reported droplet sizes are at least an average of six measurement realizations.

\subsubsection{Profilometry}

275

Bruker DektakXT Surface Profiler (Bruker Corp., USA.), which is a stylus-based surface profilometer with a vertical resolution of $1 \AA$, is used to map the height of CNCs deposited on the surface of the glass substrates after droplet evaporation. A stylus with a $6.5 \mu \mathrm{m}$ tip and $3 \mathrm{mg}$ force is used for all measurements. All experiments were carried out at least six samples and the average height profile is reported.

\subsubsection{Rheometer}

A cone-and-plate rheometer (Anton Paar-MCR 301, Austria) is used to measure the viscosity of aqueous suspensions of $\mathrm{CNC}$ with different concentrations at room temperature. All experiments were repeated at least six times and the average viscosity is reported.

A Malvern Zetasizer Ultra (Malvern, UK) is used for measuring the diffusion coefficient of cellulose nanoparticles in water using non-invasive light scattering. All experiments were repeated at least six times and the average diffusion coefficient for each case is reported.

\subsubsection{Post-Processing Methods}

ImageJ $(\mathrm{NIH})$ is utilized for post-processing the microscopy images to measure the diameter of droplets. In order to measure the surface area that is coated with $\mathrm{CNC}$, we have binarized images by imposing a global intensity threshold above which the intensity was set to one and the remaining pixel intensities were set to zero. We have then used ImageJ to measure the area covered with pixels that have the intensity of one. The jet development simulation is visualized using the EnSight software package from ANSYS. In addition, the Matplotlib library in Python is utilized to plot and analyze the data from laser diffraction and profilometry techniques.

\subsection{Governing Equations}


Three-dimensional Computational Fluid Dynamics (CFD) simulation is carried out in the open-source C++-based CFD package OpenFOAM-2.2.x ${ }^{99}$ to model the atomization and breakup of the aqueous suspension, formation of the liquid film deposited on the solid substrate, and the behavior of the droplets on the substrate that include stick, rebound, spread, and splash. ${ }^{100} \mathrm{~A}$ twodimensional domain is considered for simulating the liquid film on the solid substrate. Dynamic structure Large Eddy Simulation (LES) is implemented in this study ${ }^{101}$ to incorporate the turbulence effect of the fluid phase (liquid suspension and the surrounding gas) and StantonRutland model is employed to model film formation on the solid substrate. ${ }^{102}$ A LagrangianEulerian approach ${ }^{103}$ is used for the spray simulation that treats the gas phase as a continuum for which a complete set of transport equations are solved while the liquid phase is considered as a discrete phase transported with the gas medium. The sub-models used for the spray simulation include the dispersion model, Kelvin-Helmholtz Rayleigh-Taylor (KH-RT) breakup model ${ }^{104}$, vaporization model ${ }^{105}$, Ranz-Marshall ${ }^{106}$ heat transfer model, and dynamic structure turbulence model. For the sake of brevity, we only discuss the modified transport equations employed for solving the continuity (Eq. 1) and momentum for the liquid film deposited on the substrate (Eq. 2). For the details on Lagrangian-Eulerian spray simulations, the reader is referred to the authors' earlier works. ${ }^{107,108}$ The heat transfer on the solid substrate has been neglected here to isolate the behavior of the splashing droplets upon reaching the substrate from evaporation effects. It is noted that small droplets may have a non-Newtonian behavior due to the presence of the nanoparticles; however, as the CNC concentration is low, this study assumed a Newtonian behavior.

$$
\begin{gathered}
\frac{\partial \delta}{\partial t}+\frac{1}{A_{\text {wall }}} \sum_{i=1}^{N_{\text {side }}}\left(\vec{V}_{\text {film }} \cdot \hat{n}\right)_{i} \delta_{i} l_{i}=\frac{S_{d}}{\rho_{l} A_{\text {wall }}}, \\
\frac{\partial\left(\delta \cdot \vec{V}_{\text {film }}\right)}{\partial t}+\frac{1}{A_{\text {wall }}} \sum_{i=1}^{N_{\text {side }}} \vec{V}_{\text {film }}\left(\vec{V}_{\text {film }} \cdot \hat{n}\right)_{i} \delta_{i} l_{i} \emptyset_{i} \\
=\frac{-\sum_{i=1}^{N_{\text {side }}(P \hat{n})_{i} \delta_{i} l_{i}}}{\rho_{l} A_{\text {wall }}}+\frac{M_{\text {tang }}}{\rho_{l} A_{\text {wall }}}+\frac{\sum_{i=1}^{N_{\text {side }}} \vec{\tau} A_{i}}{\rho_{l} A_{\text {wall }}},
\end{gathered}
$$

317 The continuity and momentum equations are presented in (1) and (2), respectively and $A_{\text {wall }}$ is the

\section{8}

319

area of the wall cell, $\vec{V}_{f i l m}$ is the film velocity, $l_{i}$ is the substrate length at side i, $\rho_{l}$ is the film density, $\delta_{i}$ is the film thickness at side i, $\emptyset_{i}$ is the impingement angle, and $S_{d}$ is the source term. The following equations are used to calculate the pressure as $P=P_{\text {cell }}+P_{d}$, where $P_{\text {cell }}$ is the free stream pressure. $P_{d}$ is the dynamic pressure due to impingement and splashing of the droplets defined as follows:

$$
P_{d}=\rho_{l} \sum_{i=1}^{N_{d r o p}} V_{n d}^{2} \frac{A_{d i}}{A_{\text {wall }}}+\rho_{l} \sum_{j=1}^{N_{\text {splash }}} V_{n j}^{2} \frac{A_{j}}{A_{\text {wall }}},
$$

where $V_{n d}$ is the normal component of velocity of the incoming droplets and $V_{n j}$ is the normal component of velocity of the $j^{\text {th }}$ secondary droplet due to splashing. $A_{d i}$ and $A_{j}$ are projected areas 
325 of the $i^{\text {th }}$ incoming droplet and $j^{\text {th }}$ splashed droplet, respectively. $M_{\text {tang }}$ is the tangential momentum 326 due to the impingement and splashing of the droplets defined as follows:

$$
M_{\text {tang }}=\sum_{i=1}^{N_{\text {drop }}}\left(m_{i} \vec{V}_{\tau_{d i}}\right)-\sum_{j=1}^{N_{\text {splash }}}\left(m_{j} \vec{V}_{\tau_{j}}\right) \text {. }
$$

327 Finally, the shear force acting on the substrate due to the droplet splashing is defined as

$$
\sum_{j=1}^{N_{\text {edge }}}\left(A_{j} \vec{\tau}_{j}\right)=\sum_{i=1}^{N_{\text {splash }}}(\vec{\tau})_{\text {edge, } i} \delta_{i} l_{i}+(\vec{\tau})_{\text {wall }} A_{\text {wall }}+(\vec{\tau})_{\text {liq } / \text { air }} A_{\text {wall },}
$$

328

329

330

331

332

333

334

335

336

337

338

339

340

341

342

343

344

345

346

347

348

349

350

351

352

353

where $(\vec{\tau})_{\text {edge, } i}$ is the shear stress along the edges of the film, $(\vec{\tau})_{\text {wall }}$ is the wall shear stress, and $(\vec{\tau})_{l i q / a i r}$ is the shear stress at the interface between the gas and the liquid.

\subsection{Droplet Behaviour on the Substrate}

The droplet behavior upon reaching the substrate is detected via the droplet splashing criteria suggested by Stanton ${ }^{109}$ as outlined in Table 2. It indicates whether the droplets stick, rebound, or spread on the solid substrate depending on the frequency of the incoming impinging droplets. This criterion is based on the Weber number $(W e)$ that is defined as the ratio of the drag force to surface tension force acting on the droplets. The parameters given in Table 2 include $d_{d}$, the diameter of impinging droplet; $f$, the frequency of droplets impinging on the wall, $v$, the velocity, and $\sigma$ is the surface tension coefficient.

Table 2. Droplet splashing criteria 109

\begin{tabular}{|l|l|}
\hline Stick & $W e<5$ \\
\hline Rebound & $5<W e<10$ \\
\hline Spread & $10<W e<324 v^{1 / 4} f^{3 / 4}(\rho / \sigma)^{1 / 2}$ \\
\hline Splash & $W e>324 d_{d} v^{1 / 4} f^{3 / 4}(\rho / \sigma)^{1 / 2}$ \\
\hline
\end{tabular}

We will calculate the velocity of the droplets after rebound and the angle at which the droplets bounce off from the substrate. We will identify the position of the droplets based on their velocity upon impact with the substrate to predict the liquid film growth towards the edges of the substrate as the droplets stick to the substrate. The number density of the droplets bouncing off the substrate will be calculated. Finally, a Weibull distribution ${ }^{110}$ is used to calculate the diameter of the droplets which break down and bounce back from the surface of the liquid film on the substrate. The equations used for calculating the above-mentioned parameters are summarized in Appendix I.

\section{Results and Discussion}

\subsection{Spray Formation}

It is crucial to understand the breakup mechanisms of the supercritical $\mathrm{CO}_{2}$-assisted atomization of the aqueous CNC suspension as it creates droplets that carry and deposit the nanoparticles on the substrate. In order to fully understand the effect of different parameters on the 
deposition process and the created micro/nano structure, a wide range of test cases outlined in Table 1 are studied. The experiments are designed to encompass different phases (i.e., subcritical, critical, and supercritical phases) of the hybrid $\mathrm{CO}_{2}$-water mixture. Supercritical $\mathrm{CO}_{2}\left(\mathrm{SC}-\mathrm{CO}_{2}\right)$ has a high density and is highly soluble in water around the critical point of the $\mathrm{CO}_{2}$-water mixture, since the diffusion coefficient of $\mathrm{CO}_{2}$ significantly increases close to this critical pressure (i.e., $\sim 7.5 \mathrm{MPa}$ ). The high solubility of $\mathrm{CO}_{2}$ in water reduces the interfacial tension of the injection mixture that is shown to facilitate the atomization process ${ }^{111}{ }^{112}$. Table 3 presents the thermophysical properties of $\mathrm{CO}_{2}$-water mixture at sub-critical, critical, and supercritical states. Comparing these values shows that that optimum condition (high diffusion coefficient and low interfacial tension) is achieved at the critical pressure of the $\mathrm{CO}_{2}$-water mixture and supercritical pressure. Increasing the pressure beyond $9 \mathrm{MPa}$ does not further change the solubility and the interfacial tension. The translational diffusion coefficient of $\mathrm{CNC}$ in water is measured using dynamic light scattering (DLS) and is plotted as a function of CNC concentration in Fig. 2. By increasing the concentration of $\mathrm{CNC}$ from 0.2 to $2 \mathrm{wt} \%$, the measured diffusion coefficient decreases, and viscosity increases.

Table 3. Thermophysical properties of subcritical, critical, and supercritical $\mathrm{CO}_{2}-\mathrm{H}_{2} \mathrm{O} .{ }^{113}, 114$

\begin{tabular}{|c|c|c|c|c|}
\hline $\begin{array}{c}\text { Pressure } \\
(\mathrm{MPa})\end{array}$ & $\begin{array}{c}\mathrm{CO}_{2} \text { solubility } \\
(\mathrm{mol} \%)\end{array}$ & $\begin{array}{c}\mathrm{CO}_{2} \text { diffusion coefficient } \\
\left(\mathrm{m}^{2} / \mathrm{s}\right) \times 10^{-10}\end{array}$ & $\begin{array}{c}\text { Interfacial tension } \\
(\mathrm{mN} / \mathrm{m})\end{array}$ & Density $\left(\mathrm{kg} / \mathrm{m}^{3}\right)$ \\
\hline 3 & 1.35 & 6.7 & 56.5 & 1015.2 \\
\hline 6 & 2.15 & 15.1 & 40.8 & 1016.1 \\
\hline 7.5 & 2.35 & 18.5 & 36.2 & 1018.5 \\
\hline 9 & 2.41 & 13.9 & 33.5 & 1020.3 \\
\hline
\end{tabular}

370
High mole fraction of dissolved $\mathrm{SCO}_{2}$ in aqueous $\mathrm{CNC}$ suspension results in the formation of a bulged core filled with $\mathrm{CO}_{2}$ in the liquid jet very close to the nozzle. The emergence of gas bubbles and depressurization into the atmospheric pressure causes bubble expansion and eventually bubble burst. The force produced by the bubble burst shatters the liquid into micronsize long and slender ligaments that eventually breakup and form small droplets ${ }^{85}$. The temporal development of the bubbles and ligaments in a region close to the nozzle ( $300 \mu \mathrm{m}$ downstream of the orifice exit) is portrayed in Fig. 3. The lower interfacial tension of $\mathrm{CO}_{2}$-water mixture at supercritical conditions facilitates the ligament breakup and the combined effects result in enhanced primary breakup and formation of fine droplets with homogenous size distribution that ensures a uniform distribution of the deposited nanostructures on the substrate upon evaporation of the solvent. We have detailed the breakup mechanism of the liquid jet in the same SAA system in our earlier paper ${ }^{85}$. 


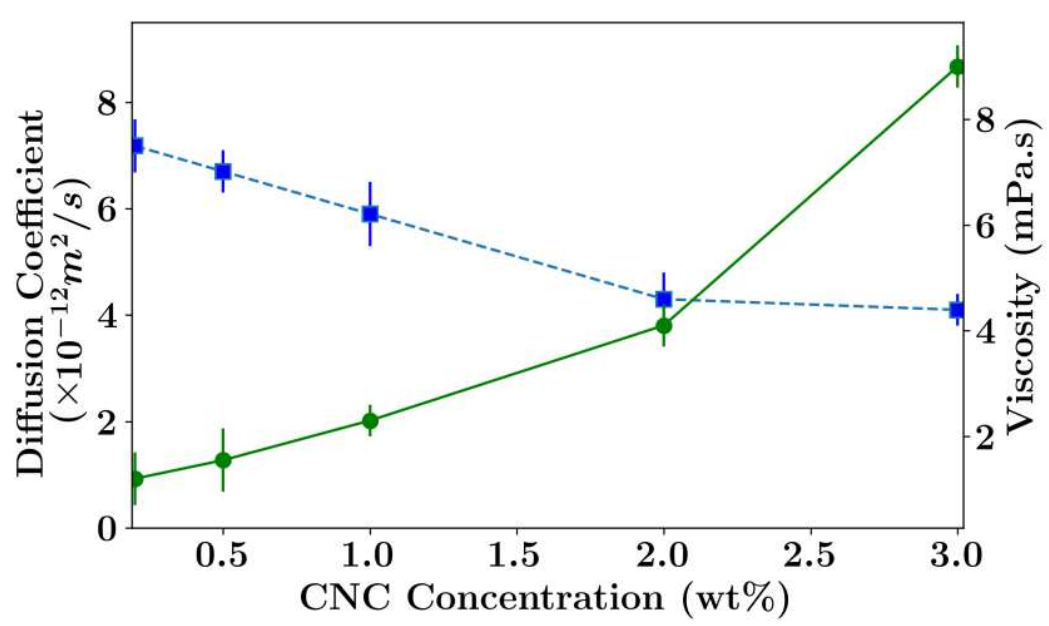

Figure 2. Diffusion coefficient of CNC in water (left axis, dashed blue line), and viscosity of aqueous CNC suspension (right axis, solid green line) as a function of CNC concentration.

The droplets created through the atomization process carry the nanoparticles and place them on the substrate. The assembly of the nanoparticles and the pattern of the deposited nanoparticles are highly affected by the droplet evaporation dynamics on the substrate and the size of the droplets. As a result, it is important to understand the effect of different spray parameters (i.e., injection pressure, gas-to-liquid ratio, axial distance from injection orifice) and injection mixture properties (i.e., the concentration of nanoparticles) on the droplet average size. These analyses will aid in designing the process parameters of the spray system. The next section discusses the effect of various process parameters on the SMD of the droplets containing nanoparticles.

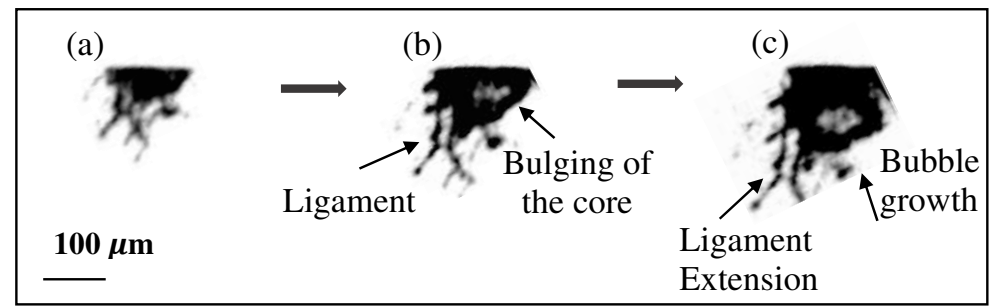

Figure 3. High-speed images (500,000 fps) capturing the early development of the spray. GLR $=0.2$, $P_{i n j}=9 \mathrm{MPa}$ developing with time from left to right with a $2 \mu$ s time interval between the frames.

\subsection{Droplet Size Distribution}

The effect of different spray parameters and physical properties of the injection mixture on the average size of carrier droplets that is especially crucial for designing the nanoparticle delivery system is discussed in this section. The laser diffraction system is used for real-time measurement of SMD at 10, 15, and $20 \mathrm{~cm}$ axially located downstream of the nozzle. These points are selected to fully represent the whole spray plume. Figure 4 plots the measured SMD as a function of GLR for different injection pressures and axial locations. It is observed in Fig. 4 (a-c) that for each injection pressure, the mean droplet size decreases as GLR increases and the rate of SMD reduction decreases with an increase in GLR and reaches a plateau at the GLR of 0.2. At this point, increasing 
409 GLR does not have a noticeable effect on the SMD and hence this value (i.e., GLR= 0.2) is selected 410 for spray deposition experiments.

411 At each GLR and axial distance, increasing the injection pressure results in the formation of 412 droplets with smaller sizes. This is owed to the higher solubility of $\mathrm{CO}_{2}$ in water and lower 413 interfacial tension of $\mathrm{CO}_{2}$-water mixture at higher pressures as was indicated in Table. 3. The 414 combined effects enhance the primary breakup of the liquid jet due to the burst of dissolved gas 415 bubbles and surface capillary breakup. As a result, the variation of droplet sizes by changing 416 injection pressure is more evident in cases where measurement is performed closer to the nozzle 417 (i.e., $10 \mathrm{~cm}$ axial distance in Fig. 4(a)) compared to measurements further away from the injection 418 orifice (i.e., 15 and $20 \mathrm{~cm}$ from the orifice in Fig. $\mathbf{4}(\mathbf{b}, \mathbf{c})$ ). It is also evident that for each injection 419 pressure, increasing the axial distance between the injection orifice and SMD probe from $10 \mathrm{~cm}$ 420 in Fig. 4 a to $20 \mathrm{~cm}$ in Fig. 4c, results in smaller mean droplet sizes and their size does not vary 421 significantly with GLR. This can be attributed to the "secondary breakup" of droplets that occurs 422 at locations further away from the nozzle. The secondary breakup is referred to a process in which 423 the droplets exposed to high shear forces breakup into multiple smaller droplets. 


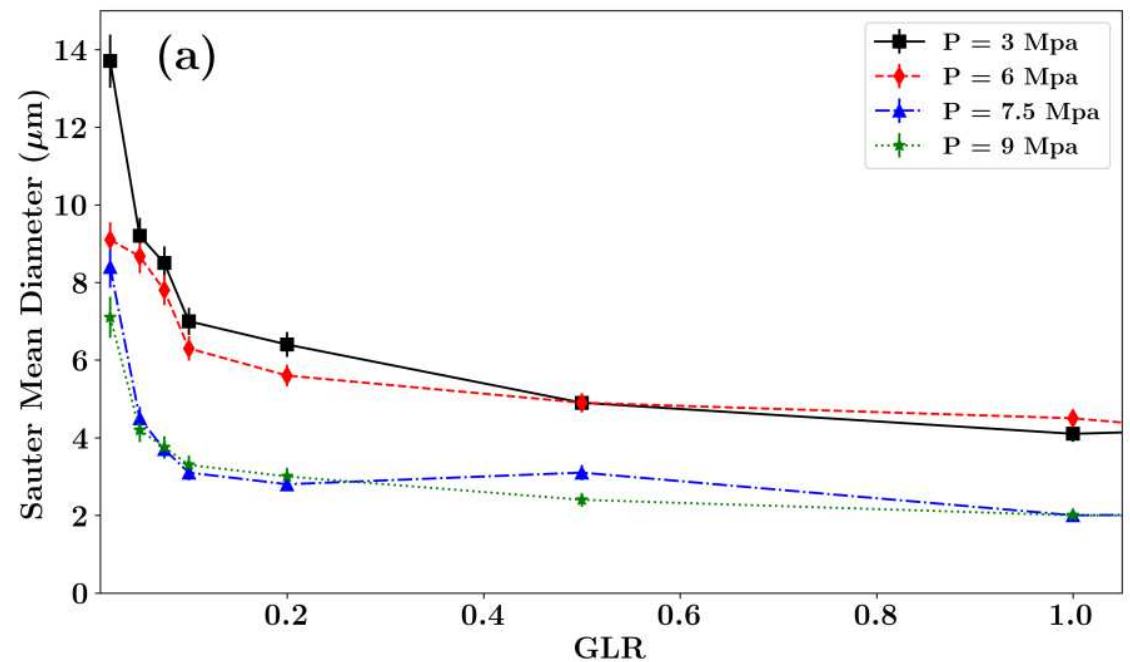

425
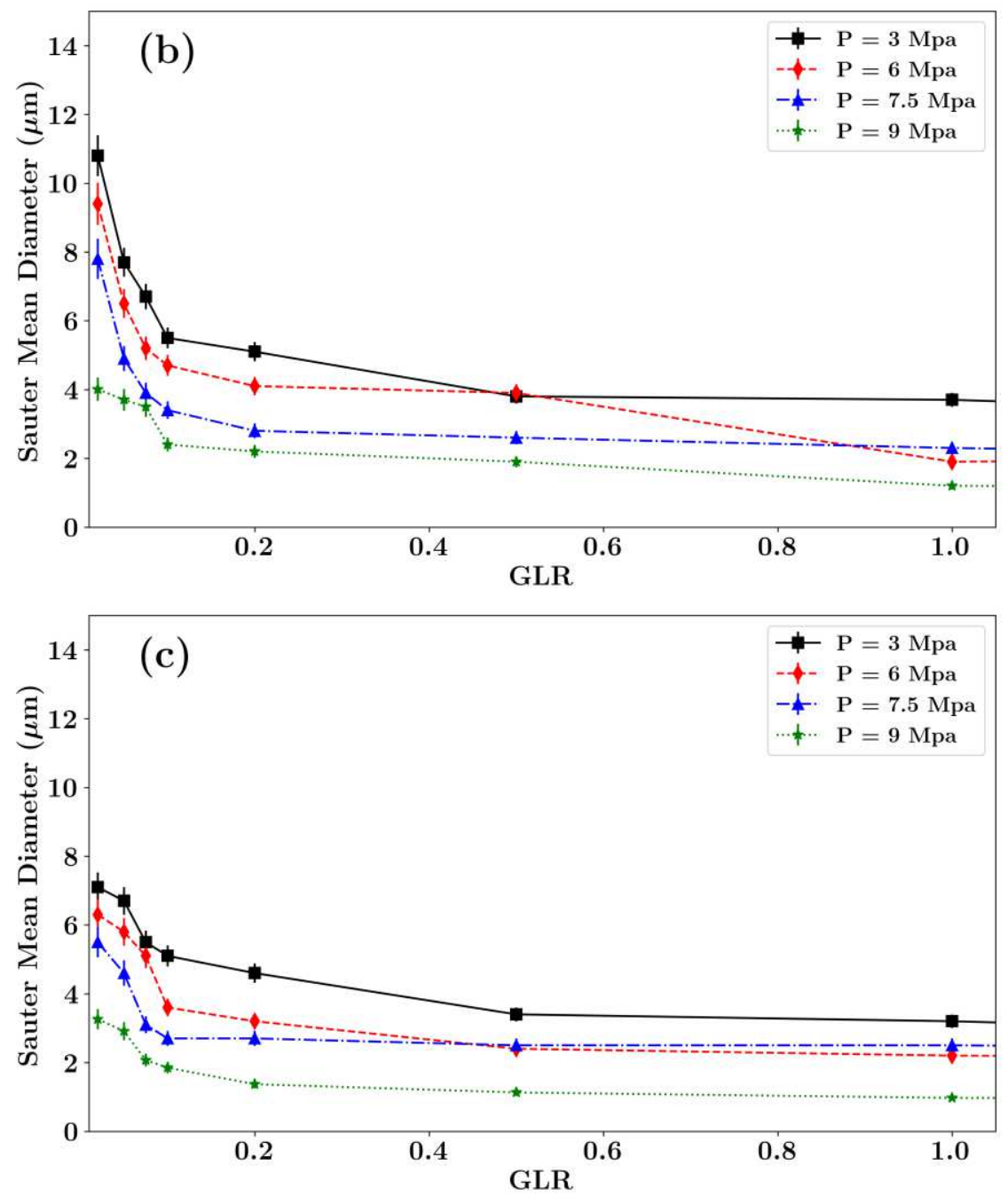

427 Figure 4. SMD measurements as a function of GLR for different injection pressures and an axial distance 428 of (a) $10 \mathrm{~cm}$, (b) $15 \mathrm{~cm}$, and (c) $20 \mathrm{~cm}$ from injection orifice. 
Figure 5(a) shows the measured SMD as a function of injection pressure at $1 \mathrm{~cm}$ axial distance with respect to the nozzle and for three different concentrations of CNC in the suspension (i.e., 0.2, 0.5, and 2wt\%). Similar to Fig. 4, increasing the injection pressure reduces the droplet sizes.

432 The droplet sizes breakup into smaller droplets at locations further away from the orifice due to the secondary breakup. The sharpest decrease in the droplet is achieved at 7.5 MPa injection pressure that is close to the critical pressure of the $\mathrm{CO}_{2}$-water mixture. The proximity to the critical pressure enhances the diffusivity of $\mathrm{CO}_{2}$ in water and the creation of more bubbles inside water upon injection that enhances the atomization process and reduces the droplet size. Further increasing the injection pressure to $9 \mathrm{MPa}$ has a negligible effect on the droplet size. This can be attributed to the maximum diffusion coefficient of $\mathrm{CO}_{2}$ in water that occurs at $7.5 \mathrm{MPa}$, ${ }^{115}$ which in turn results in minimum surface tension value for the water- $\mathrm{CO}_{2}$ mixture at this pressure. ${ }^{114} \mathrm{In}$ addition, increasing the concentration of nanoparticles in the injection mixture, from $0.2 \mathrm{wt} \%$ to $2 \mathrm{wt} \%$, increases the overall size of the carrier droplets. The viscosity of the aqueous suspension increases from 1.2 to $4 \mathrm{mPa}$.s by increasing the concentration from 0.2 to $2 \mathrm{wt} \%$ as indicated in Fig. 2. This enhancement ( $\sim$ three-fold) in viscosity of the injection mixture leads to an average of $\sim 54 \%$ growth in droplet sizes of the spray. It is well established that an increase in liquid viscosity results in the formation of larger droplets as it suppresses the breakup process by dampening the interfacial perturbations between the liquid and gas upon injection that eventually break it up to multiple droplets. ${ }^{116,117}$ The direct effect of droplet sizes on the dynamics of solvent evaporation which in turn influences the assembly of nanoparticles and architecture of nanostructures formed on the substrate is discussed in the next section.

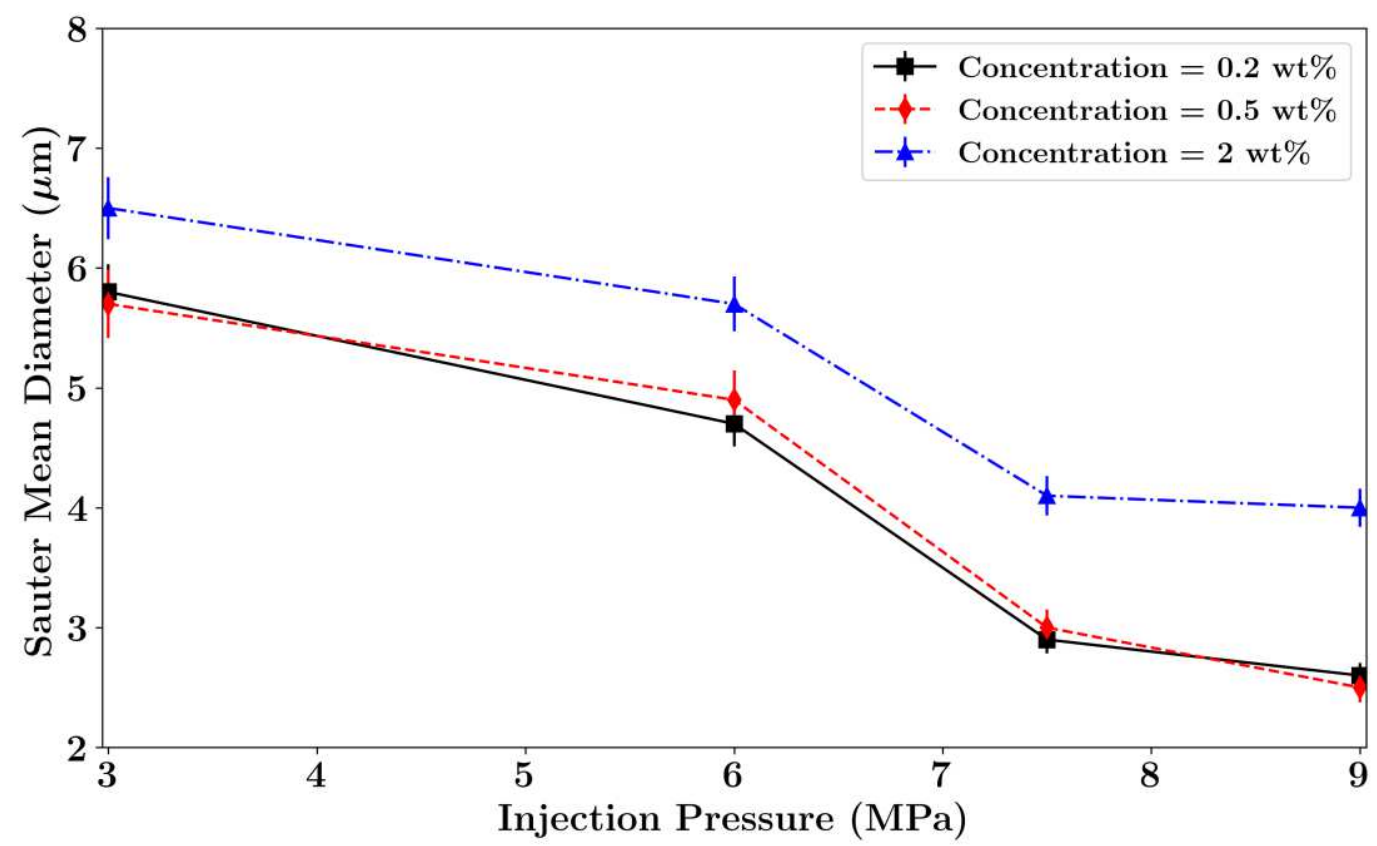

Figure 5. SMD as a function of injection pressure for different $\mathrm{CNC}$ concentrations measured at an axial distance of $15 \mathrm{~cm}$ and GLR=0.2. 
In this section, we discuss the CNC patterns that form after the evaporation of the liquid droplets generated through atomization of the aqueous CNC suspension. We study the effects of different process parameters on the created nanostructure on a glass substrate. Figures 6 visualizes the polarized micrographs of otherwise transparent CNC nanostructures that are formed on the substrate upon droplet evaporation for different injection pressures. The glass substrates are $1 \mathrm{~cm}$ by $1 \mathrm{~cm}$. Figure 6 illustrates the architecture of nanostructures for various injection pressures for $0.2 \mathrm{wt} \%$ (left column) and $2 \mathrm{wt} \%$ (right column) CNC concentration. The main pattern of assembled nanostructures in these top-view micrographs can be categorized in one of the three shapes: (1) ring-shape, where the majority of nanoparticles accumulate along the edge of the evaporating droplet, (2) homogenous distribution, where particles scatter across the surface area of the evaporating droplet, and (3) transition stage, where there is still a distinct ring-shape structure and some particles are also scattered within the center of the evaporating droplet. It is illustrated in Fig. 6(a1-d1) that regardless of the injection pressure, the droplets with diameters smaller than $\sim 5.5 \mu \mathrm{m}$ exhibit a homogenous distribution, while droplets larger than $\sim 7.5 \mu \mathrm{m}$ have generated a ringshaped structure, and droplets with diameter sizes in between the two thresholds (i.e., between 5.5 to $7.5 \mu \mathrm{m}$ ) represent a transition between the two identified regimes. All three patterns were observed for all injection pressures as the droplet size distribution envelopes the detected

472 thresholds. In Fig. 6(a2-d2) that illustrate droplets with a higher concentration of CNC particles 473 (i.e., $2 \mathrm{wt} \%$ ), the homogenous distribution, transition, and ring structure occurs for $<9.5 \mu \mathrm{m}, \sim 9.5$ $47411.5 \mu \mathrm{m}$, and $>11.5 \mu \mathrm{m}$ droplet sizes, respectively. It is noted that at least 6 images were taken at 475 different locations of the same substrate; all of which were in great agreement with the threshold 476 detected in these figures.

477

(a) $P_{i n j}=3 \mathrm{MPa}$
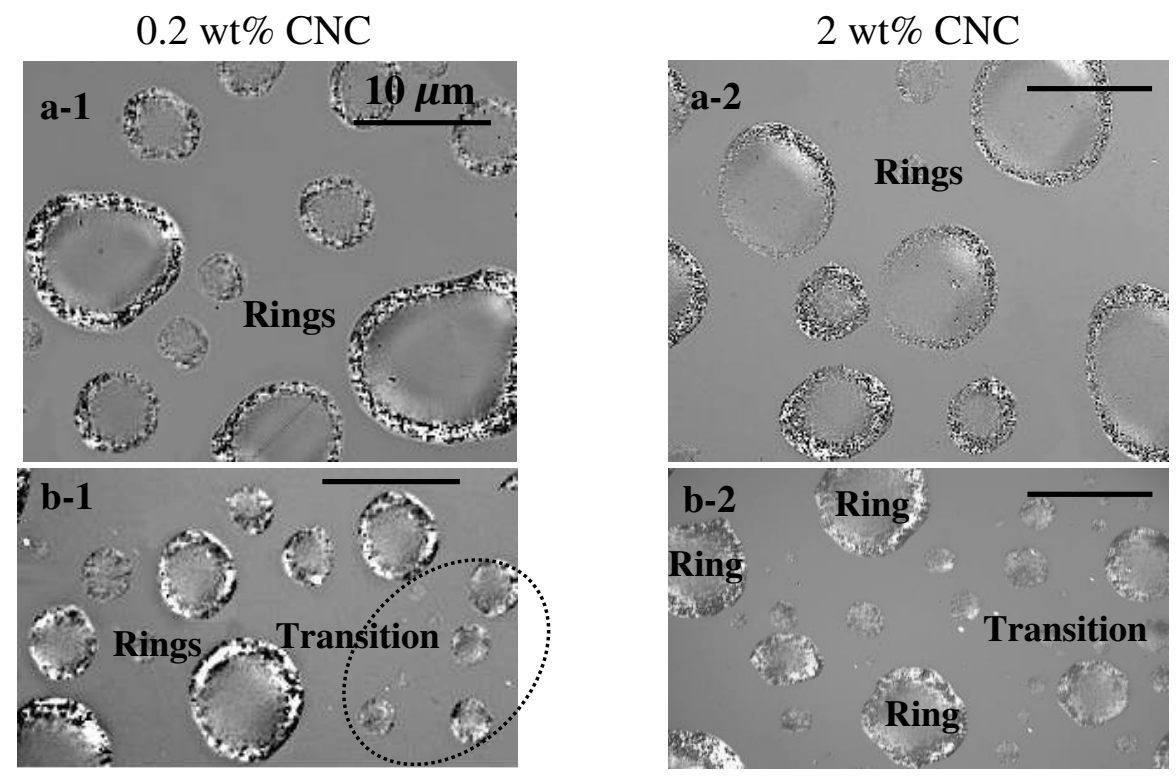
(c) $P_{i n j}=7.5 \mathrm{MPa}$
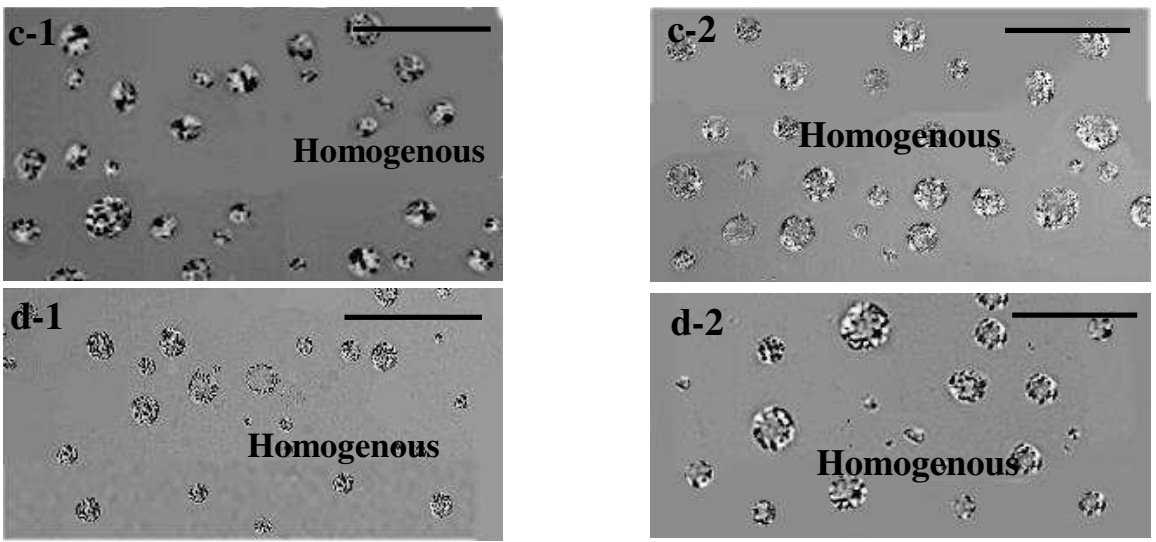

Figure 6. Polarized microscopy of $\mathrm{CNC}$ patterns after evaporation of water in $\mathrm{CNC}$ aqueous suspension droplets on a glass substrate located at $15 \mathrm{~cm}$ axial distance for $0.2 \mathrm{wt} \% \mathrm{CNC}$ concentration for (a-1) 3 $\mathrm{MPa}$, (b-1) $6 \mathrm{MPa}$, (c-1) $7.5 \mathrm{MPa}$, and (d-1) $9 \mathrm{MPa}$ injection pressures and $2 \mathrm{wt} \% \mathrm{CNC}$ concentration for (a-2) $3 \mathrm{MPa}$, (b-2) $6 \mathrm{MPa}$, (c-2) 7.5 MPa, and (d-2) $9 \mathrm{MPa}$ injection pressures. The $10 \mu \mathrm{m}$ scale bar is identical in all images.

Figure 7 demonstrates the profile/height measurements of assembled nanostructures upon evaporation for droplet sizes varying from 5 to $13 \mu \mathrm{m}$ and different concentrations (0.2wt\%, $0.5 \mathrm{wt} \%, 2 \mathrm{wt} \%)$. Combined with top-view micrographs presented in Fig. 6, they provide a 3D realization of the shape of assembled CNC nanostructures. In Fig. 7, the droplets have been injected at $9 \mathrm{MPa}$. We discussed the effect of injection pressure on the nanoparticle patterns in Fig. 6 and showed that droplets with the same size and concentration shared the same pattern regardless of the injection pressure. The profilometry height measurements indicate that nanostructures represent a ring, disk, or dome shape. A ring pattern that is identified with two peaks on the height profile is referred to the accumulation of nanoparticles along the edge of the droplet (labeled as "ring" in the top view in Fig. 6). A dome forms when nanoparticles are captured at the interface during evaporation and mainly remained in the center after droplet evaporation i.e., only one peak is observed on the height profile. The dome structure was identified as "transition" in the top view depicted in Figure 6. Finally, a disk pattern forms when the height profile is nearly flat at the center. This indicates nanoparticles are scattered more uniformly across the surface area of the droplet compared to the dome and ring and. The disk pattern was identified as "homogenous" in the top view Fig. 6. Figure 7 shows that by decreasing the droplet size from $13 \mu \mathrm{m}$ (red) down to $5 \mu \mathrm{m}$ (blue), the assembly of particles transits from ring-shape to a dome-shape structure for all CNC concentrations. The $9 \mu \mathrm{m}$-droplet (green) represents the transition between ring to a diskshape structure. By increasing the concentration of $\mathrm{CNC}$, the transition from a ring structure to disk occurs at larger droplet sizes. As will be discussed in the next section, the droplet size and concentartion directly affects the evaporation rate of the solvent, which in turn influences the particle advection and diffusion and ultimately the nanoparticle patterns. 

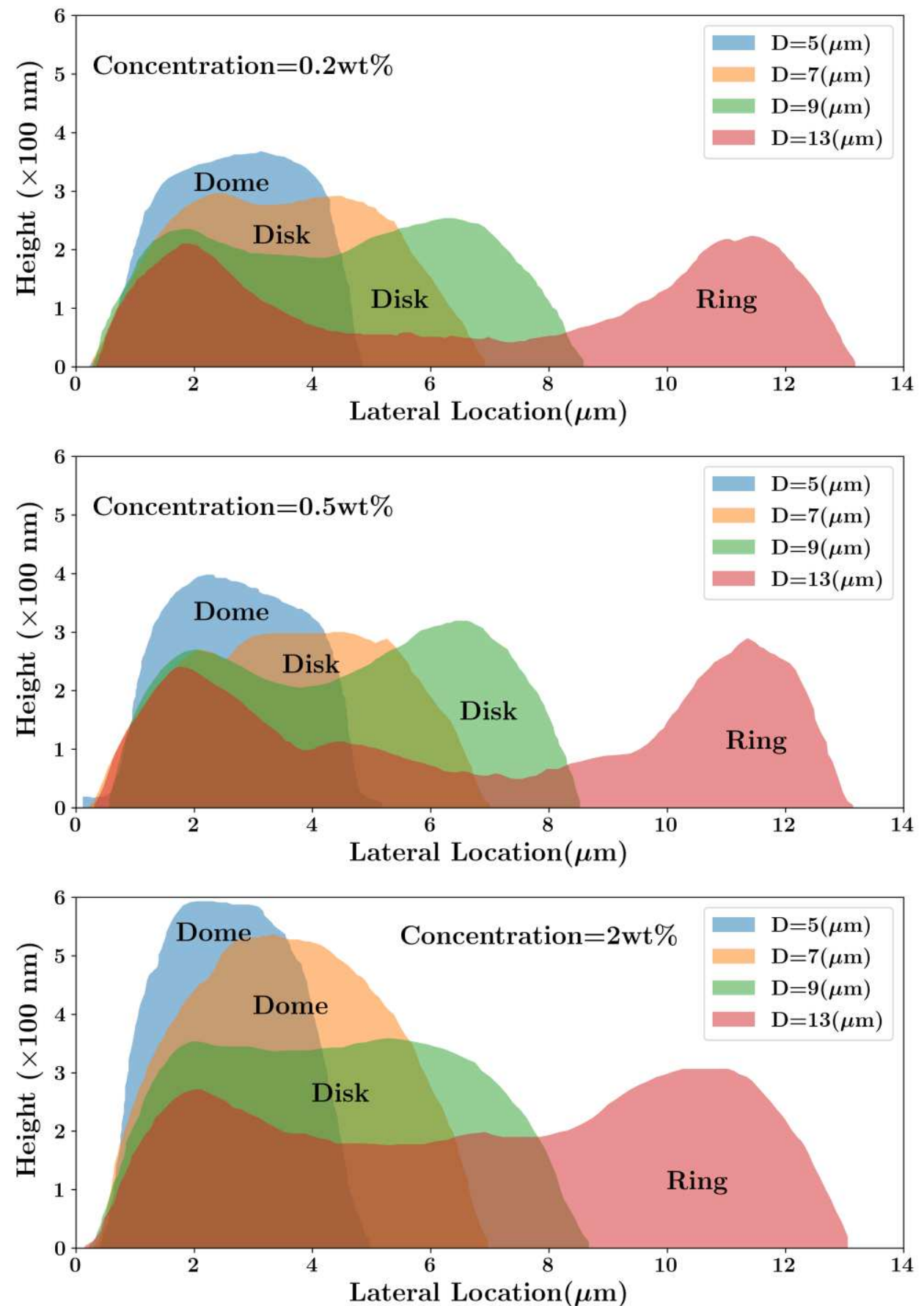

$509 \quad$ Figure 7. Profilometer height measurement of CNC nanostructures created on substrate after evaporation 510 of water in droplets as a function of droplet diameter. CNC concentrations are $0.2,0.5$, and $2 \mathrm{wt} \%$ and the 


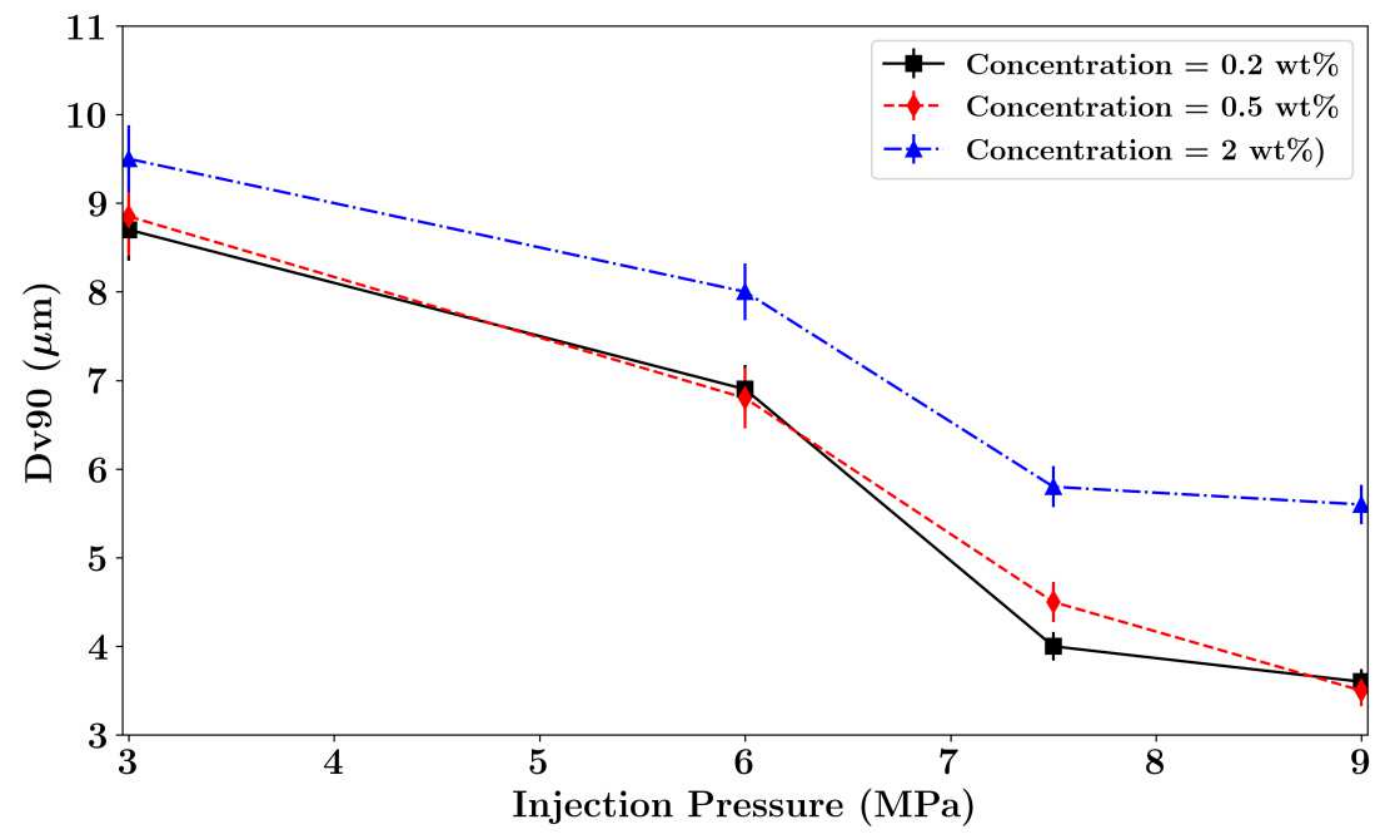

513

Figure 8. Dv90 as a function of injection pressure for different $\mathrm{CNC}$ concentrations measured at an axial distance of $15 \mathrm{~cm}$ and $\mathrm{GLR}=0.2$.

In summary, by controlling the droplet sizes we can engineer the desired pattern (ring, dome, disk) for different concentrations. The use of $\mathrm{SCO}_{2}$ enables achieving a very uniform distribution of droplet sizes within the spray that facilitates achieving a uniform distribution of $\mathrm{CNC}$ with the desired pattern on the substrate. The injection pressure can directly control the overall size of droplets within the spray plum and can be adjusted to the size requirements of the specific application where the spray deposition system is being used. To quantitatively demonstrate the control over the nanostructure patterns with the injection pressure Dv90 measurement using laser diffraction method is plotted vs. injection pressure for variable concentrations plotted in Fig. 8. Dv90 indicates the mean diameter size that represents $90 \%$ of the total volume of the existing liquid droplets Fig. 8 shows that at 7.5 MPa injection pressure and $0.2 \mathrm{wt} \% \mathrm{CNC}$ concentration, $90 \%$ of droplets are smaller than $4 \mu \mathrm{m}$ in size. Based on the microscopic images and height profilometry, droplet sizes smaller than $4 \mu \mathrm{m}$ will represent a homogenous nanoparticle distribution. As a result, most of the deposited nanostructures will exhibit a disk-shape structure. The information from this measurement combined with detailed discussions on the 3D architecture of fabricated micro/nanostructures have important implications in designing practical deposition systems to ensure that majority (> 90\%) of droplets fall under a certain category (i.e., ring versus homogenous distribution).

\subsection{Evaporation-Induced Nanoparticle Assembly}

In this section, we will explore the CNC assembly in micron-size evaporating droplets. ${ }^{118}$, ${ }^{119}$ In order to find the link between the dynamics of droplet evaporation and the formation of a specific pattern upon evaporation, two main parameters are identified: (1) droplet evaporation rate that is linked to the convective transport of $\mathrm{CNC}$ as the droplet edge recedes back during droplet evaporation; and (2) the Brownian diffusion rate of CNC in water. It has been shown that in the 
absence of other competing mechanisms e.g., external forces, special treatment of the substrate or solvent, the competition between the convective and diffusive transport of particles dictates the final pattern after droplet evaporation. ${ }^{120}$ The ratio of the convective to diffusive transport of particles during water evaporation is represented by the non-dimensional Péclet $\left(P e=r^{2} / D t_{e}\right)$ number, where ' $r$ ' is the droplet radius, ' $D$ ' is the particle mass diffusivity in the liquid phase and ' $t_{e}$ ' is the droplet evaporation time. For millimeter-sized droplets, it has been shown ${ }^{121}$ that the ring pattern is typically favored for $P e>1$ as the convective rate surpasses the diffusive rate. A reduction in the $P e$, which implies a diffusion-dominated transport, is known to mitigate the ring formation toward a more uniform particle distribution. ${ }^{122}$

Our SMD measurements of the spray suggest that the droplet sizes are below 20 microns for which measuring the droplet evaporation rate is experimentally very challenging. As an alternative approach, there are various mathematical and analytical models to calculate the evaporation rate of a sessile droplet. ${ }^{123-125}$ Larson's model (Eq. 6), which is applicable for semispherical sessile droplets, is commonly used as one of the most accurate models that has been verified empirically. 123 This model is more accurate when the Bond number is smaller than $0.1\left(B o=\frac{\rho g R h_{0}}{\sigma}\right)$ and the capillary number $\left(\mathrm{Ca}=\frac{\mu u_{r}}{\sigma}\right)$ is smaller than $1 . \mathrm{Bo}$ is the ratio of the gravitational to surface tension forces and accounts for the initial shape of the droplet whereas $C a$ is the ratio of viscous to capillary forces and accounts for deformation of the droplet during evaporation. Here $\rho, g, R, h_{0}, \sigma, \mu$, and $u_{r}$ are the density, gravitational acceleration, contact line radius, initial droplet height, liquid-air surface tension, liquid viscosity, and average radial velocity due to evaporation, respectively. We first compare the experimentally measured evaporation rate for a $1 \mu \mathrm{l}$ droplet ( $\sim \mathrm{mm}$ in radius) deposited on a glass substrate with the predictions of the Larson's model. The evaporation rate has been measured with a timer at room condition (i.e., $25^{\circ} \mathrm{C}$ temperature and $\sim 40 \%$ relative humidity). Comparing the $\mathrm{Bo}(\sim 0.07)$ and $\mathrm{Ca}\left(\mathrm{O}\left(10^{-8}\right)\right)$ for the largest droplet (i.e., 1mm radius) indicates that 564 the droplet has a spherical cap shape and satisfies the requirement for using the Larson's model (Eq. 6):

$$
\dot{m}(t)=-\pi R D(1-H) C_{v}(0.27 \theta+1.3),
$$

565 where $R, D, H, C_{v}$, and $\theta$ are the droplet radius $(1 \mathrm{~mm})$, water vapor diffusivity $\left(2.42 \times 10^{-5} \frac{\mathrm{m}^{2}}{\mathrm{~s}}\right)$, 566 relative humidity $(40 \%)$, saturated water vapor concentration ${ }^{126}\left(23.2 \frac{\mathrm{g}}{\mathrm{mm}^{3}}\right)$, and droplet contact 567 angle ( $0.369 \mathrm{rad})$, respectively. The contact angle is measured on an image that is taken normal to 568 a back-illuminated droplet deposited on a solid substrate. Larson's model predicts 709 seconds for 569 a $1 \mathrm{~mm}$ droplet to evaporate and our experimental measurement indicated 718 seconds, which is 570 in close agreement with the model prediction. The translational diffusion coefficient of CNC in 571 DI-water measured by DLS for $0.2,0.5$, and $2 \mathrm{wt} \%$ concentration (Fig. 2) is $7.18 \times 10^{-12}, 6.7 \times 10^{-12}$, 572 and $4.3 \times 10^{-12} \mathrm{~m}^{2} / \mathrm{s}$, respectively. The diffusion coefficient reduces with concentration due to the 573 packed space hindering the freedom of particles to transport. ${ }^{127}$ We use this data along with the 574 evaporation rate obtained from Larson's model and droplet sizes captured by the laser diffraction 575 measurements to calculate $P e$. 
Figure 9 shows the calculated $P e$ as a function of droplet size for different CNC concentrations. By increasing the droplet size for each concentration, the evaporation time is also increased while the diffusion coefficient is constant for the same concentration. This results in higher $P e$ at higher concentrations. According to Fig. 9, the corresponding $P e$ for a droplet size of $13 \mu \mathrm{m}$ is $1.27,1.37$, and 2.13 , for $0.2,0.5$, and $2.0 \mathrm{wt} \%$ concentration, respectively. $P e>1$ indicates the domination of the convective transport of CNC particles towards the edge of the droplet induced by the evaporation of DI-water and formation of a ring-shape structure as was depicted in Fig. 7. Droplets within the $6-8 \mu \mathrm{m}$ diameter range have an average $P e$ of $0.7,0.8$, and 1 for 0.2 , 0.5 , and $2.0 \mathrm{wt} \%$ concentration, respectively. These cases where convective and diffusion rates are almost equal were identified as the transition between ring and dome shape structures in Fig. 6. various observed patterns for different concentrations and different droplet sizes imply that in addition to the particle shape, level of hydrophilicity, the droplet size, and particle mass concentration also play a role in determining the final pattern. For instance, Fig. 7 showed that for a $9 \mu \mathrm{m}$-droplet, the pattern changed from a ring at 0.2 and $0.5 \mathrm{wt} \%$ to a disk at $2 \mathrm{wt} \%$. Our results showed that increasing the ratio of mass concentration to droplet size tends to change the pattern from ring to dome as the particles are captured at the interface between the evaporating liquid and the surrounding air before they get a chance to accumulate at the droplet periphery and dry as a

596 dome or disk after liquid evaporation.

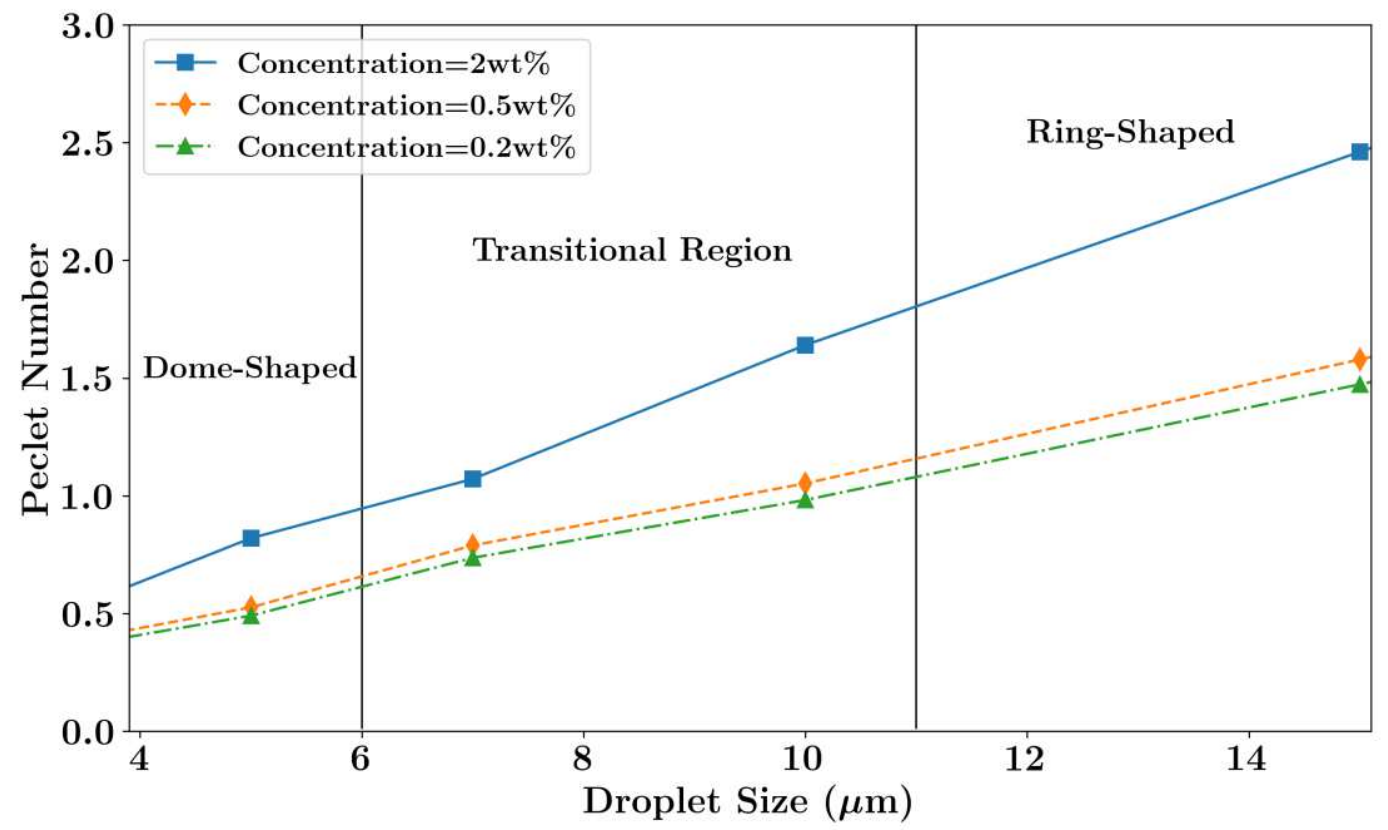

Figure 9. Peclet number as a function of droplet sizes for different $\mathrm{CNC}$ concentrations.

\subsection{Evaluating the Effectiveness of the Nanoparticle Spray Deposition Method}

Droplets created by injecting a high-pressure liquid jet toward a substrate in ambient temperature and pressure can evaporate before reaching the substrate, deposit on the substrate, or 
bounce back from the substrate before depositing their nanoparticle content on the substrate. Optimizing the distance between the injection orifice and the substrate at different injection conditions is necessary from two perspectives: (1) to predict and control the evaporation of the droplets to ensure most of the droplets containing nanoparticles reach the substrate before evaporation. This is important because if most of the droplets evaporate before reaching the substrate the nanoparticle content will be dispersed in the surrounding air and wasted; (2) to predict and control the splashing of the droplets that will affect the nanoparticle content and patterns left on the substrate. Figure $\mathbf{1 1}$ depicts a series of simulations performed to study the behavior of the spray and the resulting droplets deposited on the substrate. The black color represents the water, and the gray shows the ambient air. The droplets are observed around the core of the liquid jet due to the progression of the atomization process. The distance between the nozzle and the substrate varies from 5 to $30 \mathrm{~cm}$ with $5 \mathrm{~cm}$ increments and the tested injection pressure is $3,6,7.5$, and 9 $\mathrm{MPa}$, consistent with the experiments. The nozzle geometry selected for the simulations is consistent with the experiment (diameter of $125 \mu \mathrm{m}$ and cone-angle of $6^{\circ}$ ). For the sake of consistency, a baseline liquid film thickness of $1 \mu \mathrm{m}$ is set and when this thickness is achieved at any point on the substrate, it is assumed that the spray has reached the substrate. The simulations are conducted using pure water at room temperature without considering nanoparticles. Since the concentration of nanoparticles in water is very low in experiments the nanoparticles do not interfere with the spray behavior.

The spray development is visualized in Fig. 10 for the cases where the substrate is located at $10 \mathrm{~cm}$ axial distance from the nozzle and injection pressures are 3, 6, 7.5 and, 9 MPa. As Fig. 10 shows, increasing the injection pressure and increasing the jet momentum results in longer liquid penetration length, and thus the time taken to reach the substrate and forming the liquid film decreases from 4.8 to $2.8 \mathrm{~ms}$ by increasing the injection pressure from 3 to $9 \mathrm{MPa}$. The time required for the spray to reach the substrate is an important factor in designing experiments and setting up the optimum location of the substrate. Repeating the simulations for the cases that the substrate was located at 15 and $20 \mathrm{~cm}$ with the same injection pressures of Fig. 10 revealed that at $20 \mathrm{~cm}$, less than $1 \%$ of the droplets reached the substrate which did not result in formation of a film with $1 \mu \mathrm{m}$ thickness. These simulations suggest that the substrate should be placed at an axial distance less than $20 \mathrm{~cm}$ from the nozzle to ensure a liquid film of $1 \mu \mathrm{m}$ thickness is formed on the nozzle between $3 \mathrm{~ms}$ (for 6, 7.5, and $9 \mathrm{MPa}$ ) to $4 \mathrm{~ms}$ (for $3 \mathrm{MPa}$ ) after the start of injection. presented in Fig. 6. 

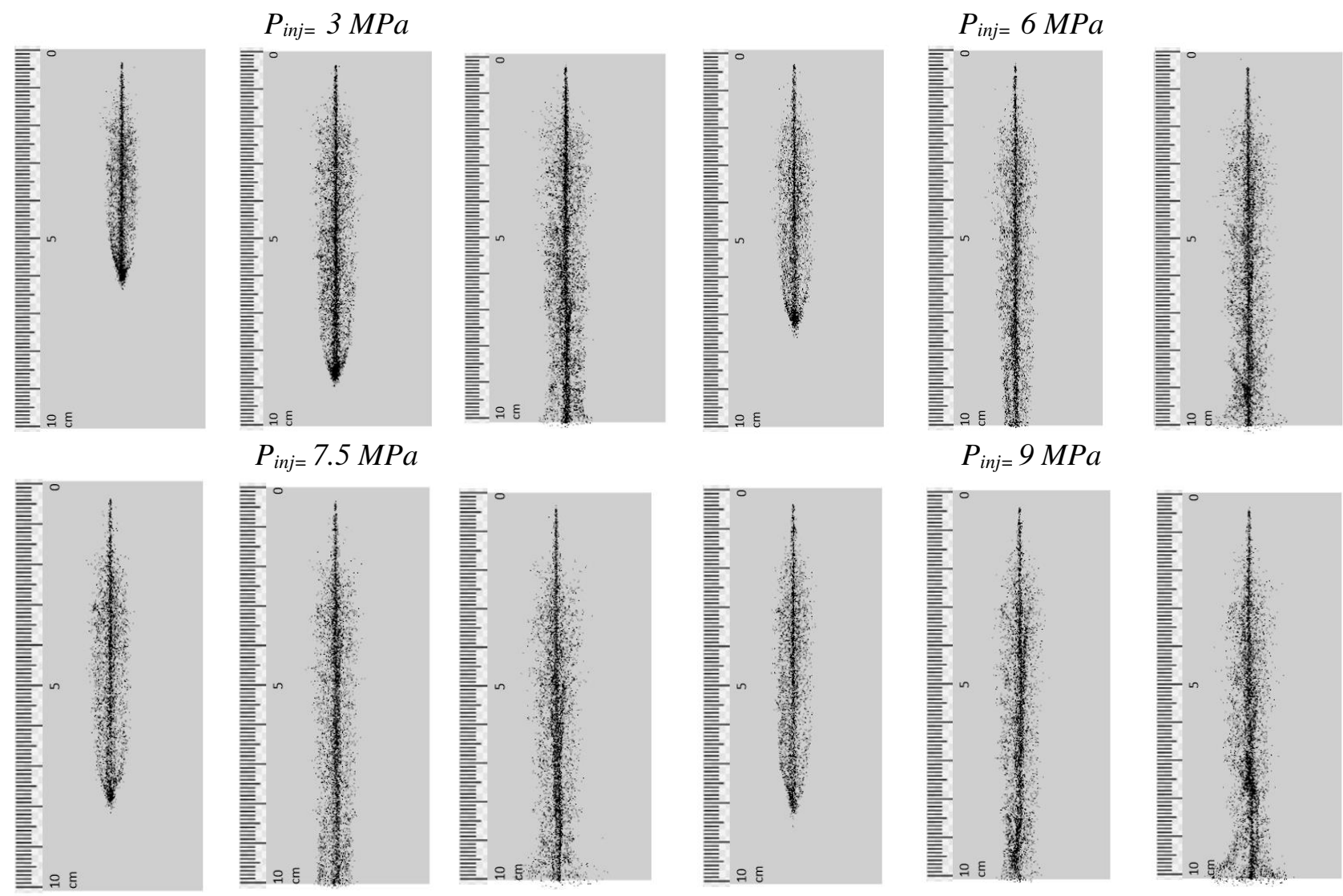

$P_{i n j=}=7.5 \mathrm{MPa}$
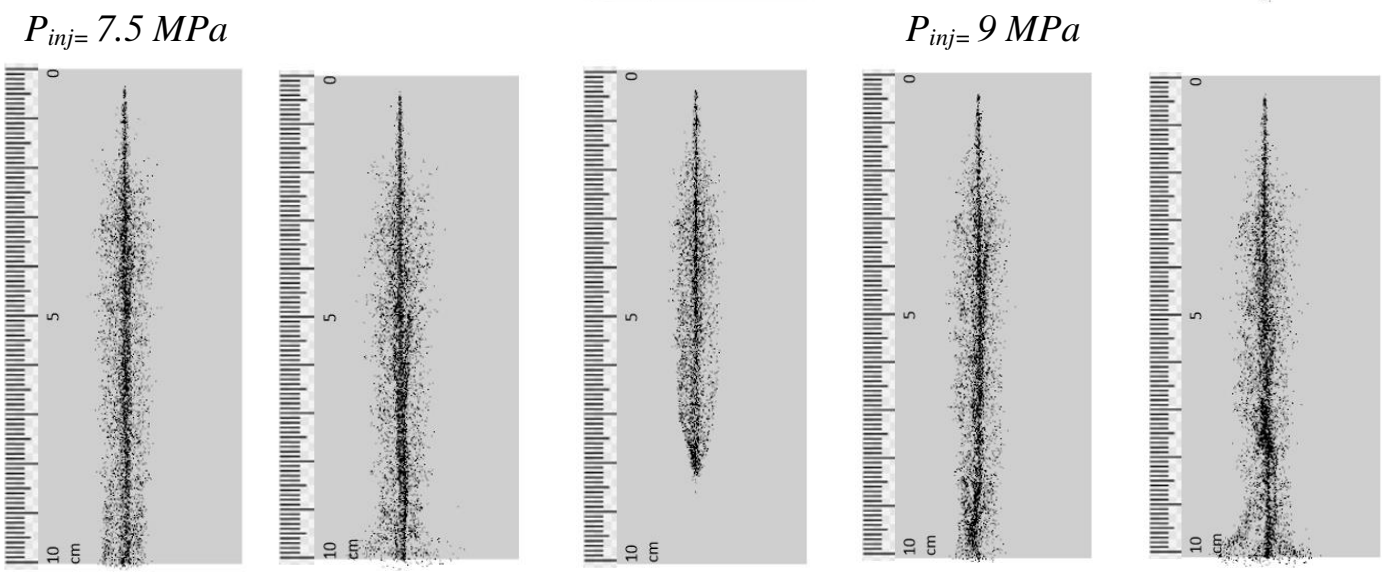

$$
t=2 \mathrm{~ms}
$$

$3 \mathrm{~ms}$

$2 m s$

$3 \mathrm{~ms}$

$5 \mathrm{~ms}$

Figure 10. Computational simulation of spatio-temporal evolution of the spray with different injection pressures at $10 \mathrm{~cm}$ distance from nozzle. The black color represents the injected water and gray background represents the surrounding ambient air. The scale bar is identical in all images.

Since droplet evaporation before the spray reaches the substrate is essential in efficiently delivering the nanomaterial to the substrate it is imperative to calculate the mass of evaporated droplet as a percentage of the total injected mass as shown in Fig. 11 for different injection pressures and nozzle-substrate distance. For each injection pressure, increasing the distance between the nozzle and the substrate increases the evaporated mass. The plots reach a plateau once the spray reaches the substrate indicating a relatively constant rates of evaporation. It is seen that for 5 and $10 \mathrm{~cm}$ positions, the mass loss due to evaporation of the droplets is in the range of 10$15 \%$ and $20-25 \%$, respectively. However, the mass loss reaches $25-30 \%$ range for 15 and $20 \mathrm{~cm}$ from the nozzle. These observations suggest that placing the substrate at a distance lower than 20 $\mathrm{cm}$ below the injection orifice minimizes the mass loss due to evaporation for the explored pressure range of 3 to $9 \mathrm{MPa}$. 

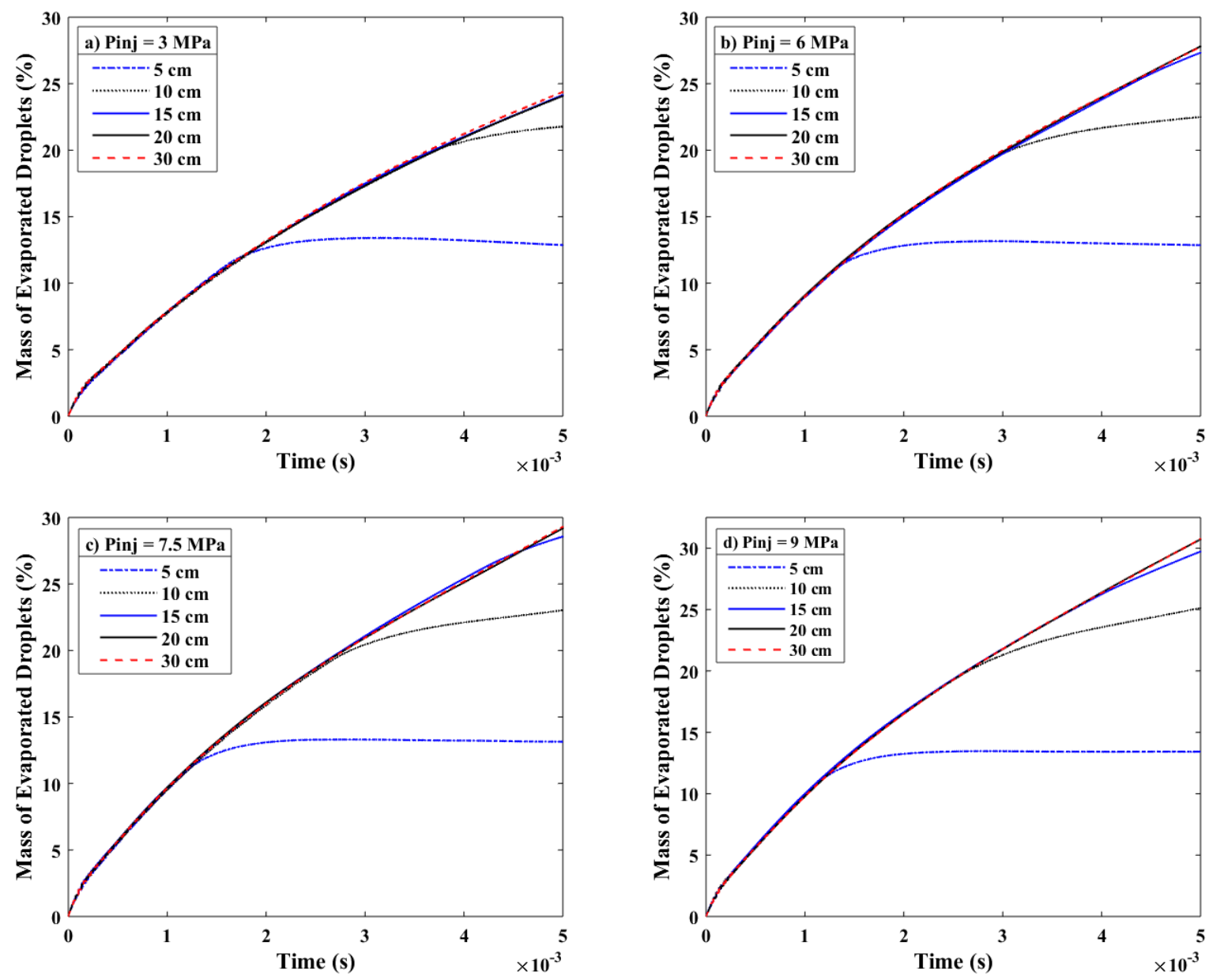

656

657

658

659

660

661

662

663

664

665

666

667

668

669

670

671

672

673

Figure 11. Temporal variation of the percentage of the mass of evaporated droplets with changes in the distance from the nozzle to the substrate at different injection pressures.

Figure 12 shows the variation in the percentage of the water mass deposited on the substrate for different injection pressures for substrate positioned at 5,10 , and $15 \mathrm{~cm}$ from the orifice. The mass of water deposited on a substrate located $5 \mathrm{~cm}$ below the injection point is $\sim 65 \%$ of the total initial mass upon injection, whereas for a $10 \mathrm{~cm}$ distance, $25-30 \%$ of its initial mass is deposited. This suggests that the remaining droplets either evaporated or scattered in the surrounding air without reaching the substrate. For 20 and $30 \mathrm{~cm}$ nozzle-substrate distance not shown in Fig. 12, the simulations predict negligible droplet deposition on the substrate implying that most of the droplets have evaporated before reaching the substrate. At each axial location, increasing the injection pressure results in the delivery of higher portions of the initial mass of droplets to the substrate. However, there is a slight decrease in the deposited mass at $9 \mathrm{MPa}$ injection pressure for the 10 and $15 \mathrm{~cm}$ cases. This is because $9 \mathrm{MPa}$ injection pressure generates smaller droplets (as is shown in Fig. 4 and 5) which are more prone to evaporation before reaching the substrate. These results suggest that 6 and $7 \mathrm{MPa}$ injection pressures are more appropriate for optimum spray deposition as droplets have large enough momentum to reach the substrate yet the mass of evaporated droplets is smaller than the $9 \mathrm{MPa}$ case before reaching the target substrate. Satisfying 
674 these two conditions ensures more efficient delivery of the nanoparticles. In addition, comparing 675 the experimental measurements of SMD at 7.5 MPa (Figs. 4 and 5) demonstrated a more uniform 676 and smaller droplet size distribution.

677

678

679

680

681

682

683

684

685

686

687

688

689

690

691

692

693

694

695

696

697

698

699

700

701

702

703
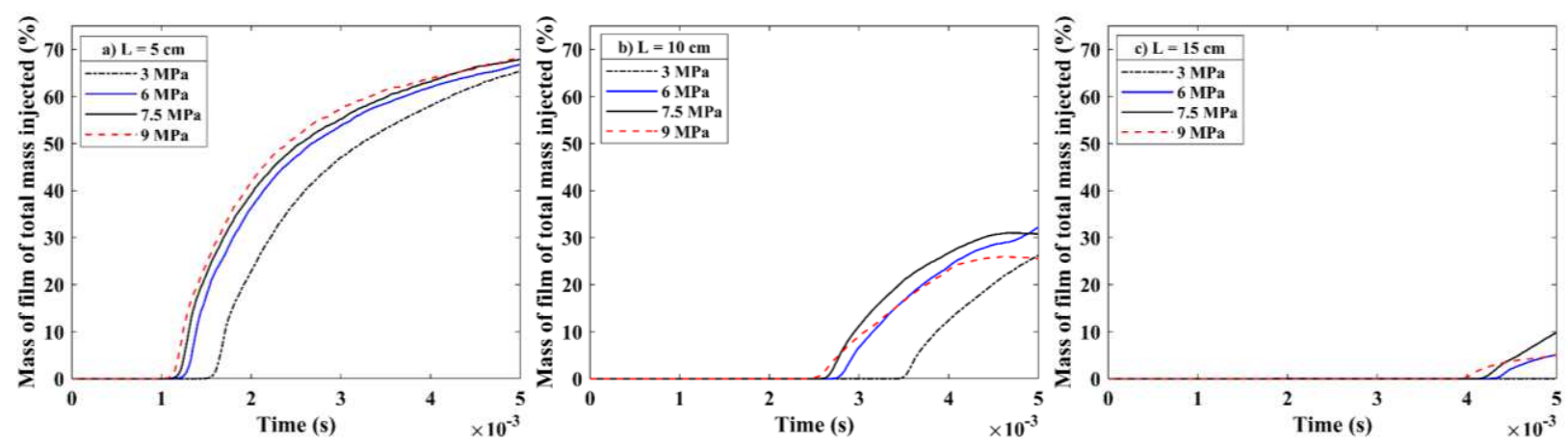

Figure 12. Temporal variations of the mass of water added to the substrate with the change in injection pressures for 5, 10 and $15 \mathrm{~cm}$ distance between the nozzle and the substrate.

The droplet bounce-back upon contact with the substrate is another important factor that affects the effectiveness of the nanoparticle deposition on the substrate. Figure 13 represents the water loss due to splashing from the substrate for axial distances of 5 and $10 \mathrm{~cm}$. As expected, the percentage of the liquid mass bounced back into the surroundings $(\sim 0.5-1 \%)$ is higher at $5 \mathrm{~cm}$ where the droplets have a higher momentum upon interacting with the substrate. The mass of bounced droplets at 15 and $20 \mathrm{~cm}$ distance are negligible, hence not depicted here. Increasing the injection pressure to $9 \mathrm{MPa}$ results in higher splashing at the film interface as the droplets gain a higher momentum upon injection. While positioning the substrate closer to the nozzle may not seem ideal for a stable film formation due to increased splashing, the percentage of droplets that are lost due to the bounce-back effect is much lower than the evaporation mass loss (1\% versus $20 \%)$.

Moreover, the higher number of bounced droplets will lead to higher film spread. This happens when the droplets that have already bounced from the substrate lose momentum and fall back on the substrate. The temporal variation of the surface coverage and iso-scales of the covered area by the spray are depicted Fig. 14. The film area calculated for $5 \mathrm{~cm}$ distance between the nozzle and substrate (colored with a film thickness of $0.01 \mu \mathrm{m}$ ) is larger due to enhanced splashing and subsequent deposition. This eventually leads to higher deposition of nanoparticles and a larger film front where the nanoparticles accumulate. It can also be seen that there is no deposition for $10 \mathrm{~cm}$ case at $2 \mathrm{~ms}$ due to larger distance between nozzle and substrate as compared to the $5 \mathrm{~cm}$ case. Considering different behaviors of droplets (evaporation, deposition, bounce-back) relative to the axial distance of the substrate observed from simulations, it is concluded that a location between $10-15 \mathrm{~cm}$ below the nozzle and 7.5 MPa injection pressure results in a more effective and uniform nanoparticle deposition 

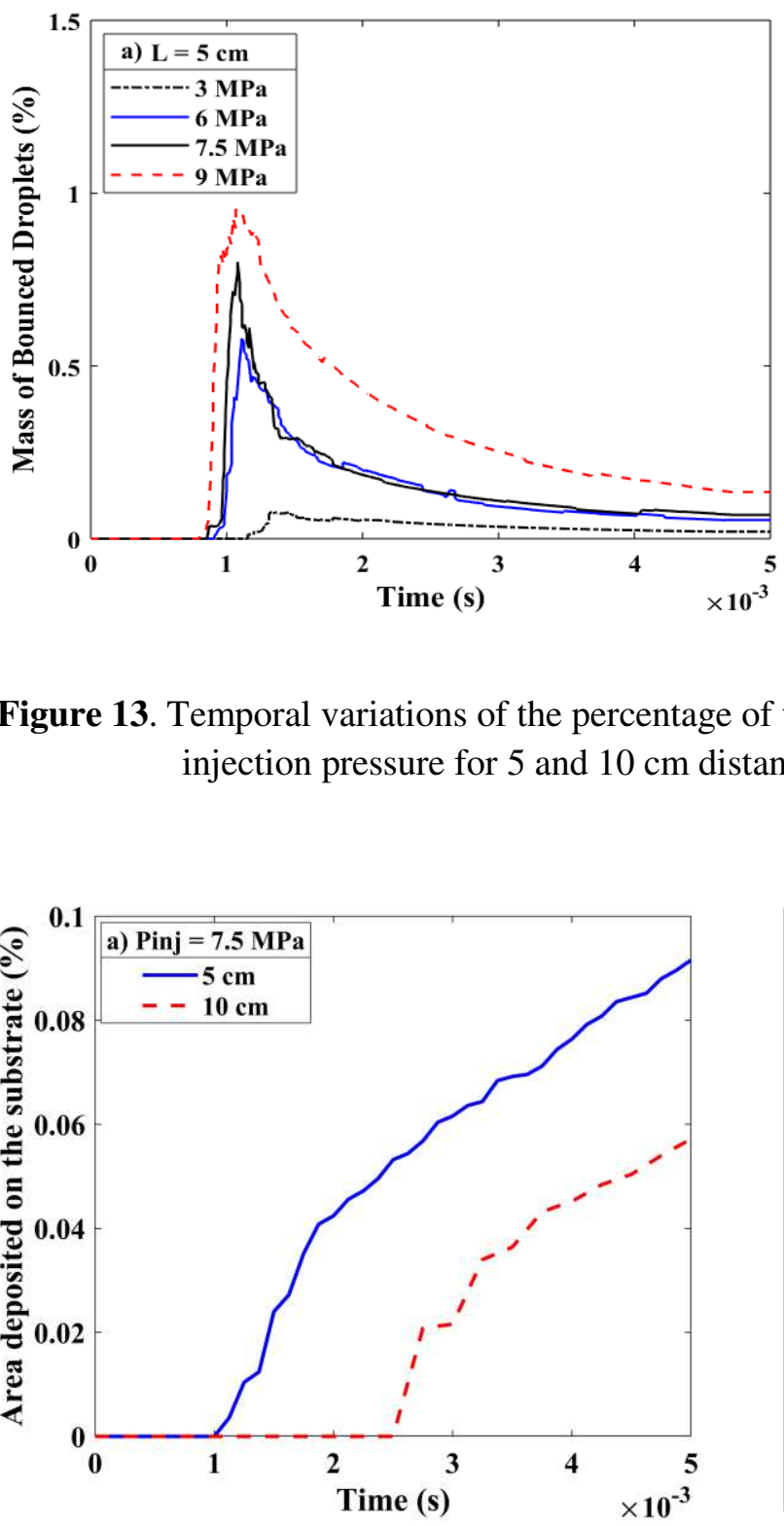
$\mu \mathrm{m}$ film thickness

\section{Summary and Conclusions}

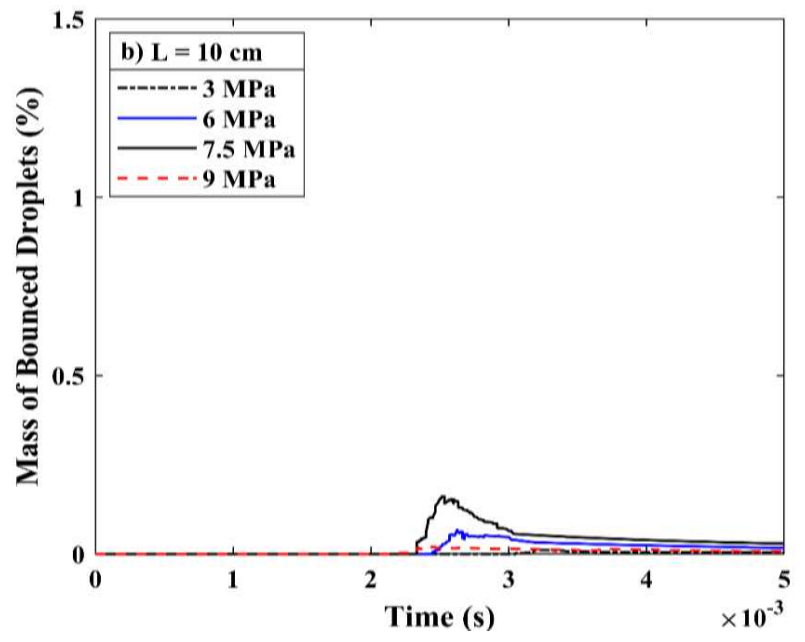

Figure 13. Temporal variations of the percentage of the mass of bounced droplets from the substrate with injection pressure for 5 and $10 \mathrm{~cm}$ distance between the nozzle and the substrate.

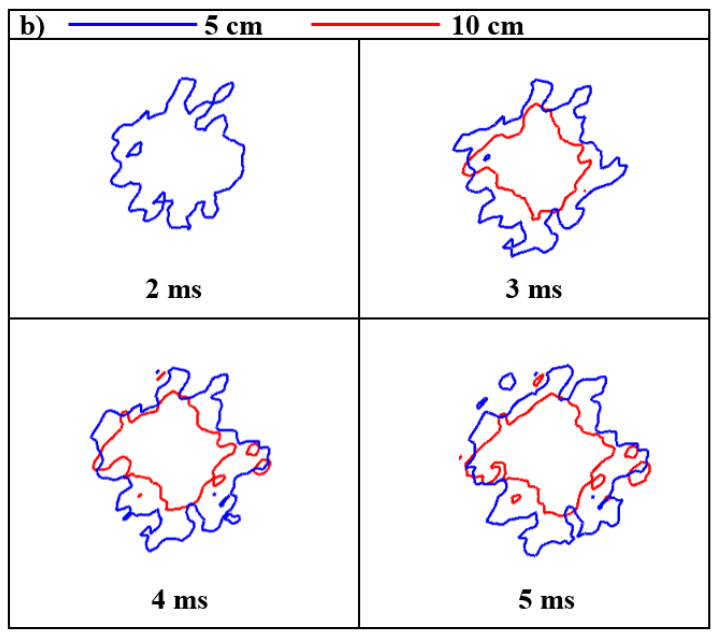

Figure 14. Temporal variation of the surface covered on the substrate by the film formed due to droplet deposition for 5 and $10 \mathrm{~cm}$ distance between the nozzle and the substrate at $7.5 \mathrm{MPa}$ injection pressure: (a) percentage of the substrate surface covered, (b) iso-scales depicting droplet deposition of over 0.01

In this study, we designed and built a novel nanoparticle spray deposition system that utilizes supercritical $\mathrm{CO}_{2}$ to assist the atomization process and create uniform micron-size CNCcarrier aqueous droplets and deposit them onto the substrate to form tailored nanostructures upon evaporation of water. The effect of spray parameters on formation of droplets were studied numerically and experimentally. The main conclusions from this work can be summarized as follows: 
1. Supercritical $\mathrm{CO}_{2}$-assisted atomization sparks two concurrent mechanisms to boost liquid atomization: reducing the liquid surface tension and enhancing $\mathrm{CO}_{2}$ dissolution in water. The combined effect results in the formation of fine droplets with a narrow size distribution that can be used as nanoparticle-carrier droplets.

2. Laser diffraction measurement of SMD shows that in general, increasing the injection pressure, GLR, and axial distance from the injection orifice results in the creation of smaller droplets. In addition, increasing the concentration of CNC in the injection mixture increases the overall size of the carrier droplets.

3. However, increasing the injection pressure above the critical pressure of the $\mathrm{CO}_{2}$-water mixture (i.e., 7.5 MPa) and increasing the GLR do not noticeably decrease the droplet sizes. This means there is no need for extremely high pressures or excessive amount of assisting gas to create micron-sized droplets.

4. Microscopic visualization of the assembled nanoparticles on the substrates illustrates that morphology of nanostructures falls into three main categories: (1) ring-shape pattern, where the majority of nanoparticles accumulate along the edge of the evaporating droplet, (2) homogenous distribution or disk pattern, where particles scatter more uniformly across the surface area of the evaporating droplet, and (3) transition stage, where there is still a distinct ring-shape structure yet some particles are scattered within the edges of the evaporating droplet.

5. The profilometry height measurements combined with micrographs provide a 3D visualization of the assembled nanostructure and show that they either form a ring, disk, or dome-shaped architecture. Increasing the mass concentration to droplet size ratio shifts the morphology of assembled nanoparticles from ring to dome as the particles are trapped at the liquid-air interface before they get a chance to move towards the edge of the droplet.

6. For each $\mathrm{CNC}$ concentration and regardless of the injection pressure, there is a droplet size threshold range above which the assembled nanostructures exhibit a ring pattern and below that they exhibit a homogenous distribution. For concentration of $0.2 \mathrm{wt} \%$, the lower and upper bounds of the threshold are 5.5 and $7.5 \mu \mathrm{m}$, respectively while for $2 \mathrm{wt} \% \mathrm{CNC}$ concentration these values increase to $9.5 \mu \mathrm{m}$ and $11.5 \mu \mathrm{m}$, respectively.

7. The injection pressure on the other hand dictates the size of the majority of droplets within the spray plume and can be used to design a system where the bulk of droplets fall under one of the identified nanostructure patterns.

8. The size of the carrier droplets strictly influences the evaporation rate of solvent in particlecarrier droplets upon deposition on the substrate. The evaporation rate in turn, affects the prevalence of convective to diffusive transport of particles that is represented by Peclet number.

9. The evaporation time is prolonged by increasing the droplet size for each concentration, which results in $P e>1$ that indicates the higher rate of convective transport of particles to diffusive transport leading to accumulation of particles along the periphery of the droplet 
and formation of a ring-shaped structure. At $P e<1$ where the diffusive movement of CNCs is dominant, a dome-shaped structure is formed for all tested concentrations. At $P e \sim 1$, droplets fall in the transitional region where both ring and dome-shaped structures are observed.

10. Computational simulations show that considering different droplet behavior interacting with the substrate (evaporation, deposition, bounce-back) versus the injection pressure and axial distance between the substrate and nozzle, positioning the substrate at 10 or $15 \mathrm{~cm}$ below the nozzle and 7.5 MPa injection pressure result in a more effective and uniform nanoparticle deposition.

\section{Declarations}

Availability of data and materials: All the data and materials supporting the claims herein are included in the manuscript and comply with the field standards.

Conflict of interest: The authors declare no conflict of interest

Funding sources: Not applicable

Code Availability: Not applicable 


\section{Appendix I}

785 Splashed mass ratio that is the mass ratio for the incident droplet mass to the splashed droplet mass 786 is calculated as below which is dependent on $u$.

$$
M_{\text {ratio }}=-27.2+3.15 u-0.116 u^{2}+0.0014 u^{3}
$$

Where,

$$
u=V_{n d}\left(\frac{\rho}{\sigma}\right)^{1 / 4} v^{-1 / 8} f^{-3 / 8}
$$

787 The position of the droplets can be calculated using the velocity of the droplets splashed into the 788 domain. This helps in predicting the film flow towards the edges. The Weibull distribution for 789 velocity is dependent on the impingement angle for the normal component. The following 790 equations help resolve the velocity:

$$
P d f_{i}\left(\frac{V_{n i}}{V_{n d}}\right)=\left(\frac{b_{v}}{\theta_{v}}\left(\frac{\frac{V_{n i}}{V_{n d}}}{\theta_{v}}\right)^{b_{v}-1}\right) \exp \left(-\left(\frac{\frac{V_{n i}}{V_{n d}}}{\theta_{v}}\right)\right)^{b_{v}}
$$

791 where, $b_{v}=2.1$ when $\theta_{i} \leq 50^{\circ}$ and $b_{v}=1.10+0.020 \theta_{i}$ when $\theta_{i} \geq 50^{\circ}$. Also, $\theta_{v}=0.158 e^{0.017 \theta_{i}} \theta_{i}$ 792 is the impingement angle. The splashed drop refection angle is calculated as $\theta_{s}=65.4+0.266 \theta_{i}$

$$
\begin{aligned}
& V_{\tau i}=\frac{V_{n i}}{\tan \theta_{s}} ; V_{n i}^{\prime}=\sqrt{K} V_{n i} ; V_{\tau i}^{\prime}=\sqrt{K} V_{\tau i} \\
& K=\frac{\frac{1}{2} m_{d} v_{d}^{2}+\pi \sigma N_{d} d_{d}^{2}-\frac{1}{2} m_{d} v_{s}^{2}}{\frac{1}{2} \sum_{i=1}^{N_{\text {parcel }}} m_{i} v_{i}^{2}+\pi \sigma \sum_{i=1}^{N_{\text {parcel }}} N_{i} d_{i}^{2}}
\end{aligned}
$$

793 Here, $V_{n i}$ and $V_{n d}$ are the splashed and incoming drop velocities. Where, $V_{s}=18\left(\frac{\sigma}{\rho}\right)^{1 / 4} v^{1 / 8} f^{3 / 8}$ 794 and frequency of the first drop is $f=\frac{V_{n d}}{X_{C F D} \text { cell }}$

795 Finally, the splashed droplet diameter which determines number of particles in each parcel is 796 defined below. A Weibull distribution shown below is used for the calculation of the splashed drop 797 diameter:

$$
P d f_{i}\left(\frac{d_{n i}}{d_{n d}}\right)=\left(\frac{b}{\theta_{w}}\left(\frac{\frac{d_{i}}{d_{d}}}{\theta_{w}}\right)^{b-1}\right) \exp \left(-\left(\frac{\frac{d_{i}}{d_{d}}}{\theta_{w}}\right)\right)^{b}
$$


798 where, $b=2.71-\left(9.25 * 10^{-4}\right) W e$ and $\theta_{w}=0.210-\left(7.69 * 10^{-5}\right) W e$. Also, $d_{i}$ and $d_{d}$ are 799 splashed and incoming drop diameters, respectively. The number of particles for the $i^{\text {th }}$ parcel is $800 N_{i}=N_{\text {tot }} p d f_{i}$ and $N_{\text {tot }}$ is the total number of splashed particles calculated by the following 801 equation:

$$
\frac{\pi}{6} N_{\text {tot }} \sum_{i=1}^{N_{\text {parcel }}}\left(p d f_{i} d_{i}^{3}\right)=\frac{m_{s}}{m_{d}} m_{d_{d}}
$$

802

803

$$
M_{\text {ratio }}=-27.2+3.15 u-0.116 u^{2}+0.0014 u^{3} u=V_{n d}\left(\frac{\rho}{\sigma}\right)^{1 / 4} v^{-1 / 8} f^{-3 / 8} P d f_{i}\left(\frac{V_{n i}}{V_{n d}}\right)
$$

804

$$
\begin{aligned}
& =\left(\frac{b_{v}}{\theta_{v}}\left(\frac{V_{n i}}{V_{n d}}\right)^{\theta_{v}}\right) \exp \left(-\left(\frac{V_{n i}}{\theta_{n d}}\right)\right)^{b_{v}} V_{\tau i}=\frac{V_{n i}}{\tan \theta_{s}} ; V_{n i}^{\prime}=\sqrt{K} V_{n i} ; V_{\tau i}^{\prime} \\
& =\sqrt{K} V_{\tau i} K=\frac{\frac{1}{2} m_{d} v_{d}^{2}+\pi \sigma N_{d} d_{d}^{2}-\frac{1}{2} m_{d} v_{s}^{2}}{\frac{1}{2} \sum_{i=1}^{N_{p a r c e l}} m_{i} v_{i}^{2}+\pi \sigma \sum_{i=1}^{N_{\text {parcel }}} N_{i} d_{i}^{2}} P d f_{i}\left(\frac{d_{n i}}{d_{n d}}\right)
\end{aligned}
$$$$
=\left(\frac{b}{\theta_{w}}\left(\frac{\frac{d_{i}}{d_{d}}}{\theta_{w}}\right)^{b-1}\right) \exp \left(-\left(\frac{\frac{d_{i}}{d_{d}}}{\theta_{w}}\right)\right)^{b} \frac{\pi}{6} N_{\text {tot }} \sum_{i=1}^{N_{\text {parcel }}}\left(p d f_{i} d_{i}{ }^{3}\right)=\frac{m_{s}}{m_{d}} m_{d_{d}}
$$$$
V_{\tau d}^{\prime}=\frac{5}{7} V_{\tau d}
$$

$$
V_{n d}^{\prime}=\frac{5}{7} V_{n d}
$$

$$
\begin{gathered}
e=0.993-1.76 \theta_{I}+1.56 \theta_{I}^{2}-0.49 \theta_{I}^{3} \\
\varphi=-\frac{\pi}{\beta} \ln \left(1-p\left(1-e^{-\beta}\right)\right)
\end{gathered}
$$

806 where $p$ is in the $[0,1]$ range and $\beta$ is given by the following equation:

$$
\sin \alpha=\left(\frac{e^{\beta}+1}{e^{\beta}-1}\right) \frac{1}{1+(\pi / \beta)^{2}}
$$

807 where $\alpha$ is the wall inclination angle measured from wall normal. 
809 1. Huang, S.; Vignolles, M.-L.; Chen, X. D.; Le Loir, Y.; Jan, G.; Schuck, P.; Jeantet, R., Spray drying of probiotics and other food-grade bacteria: A review. Trends in food science technology $8112017,63,1-17$.

812 2. Gharsallaoui, A.; Roudaut, G.; Chambin, O.; Voilley, A.; Saurel, R., Applications of spray813 drying in microencapsulation of food ingredients: An overview. Food research international 2007, 81440 (9), 1107-1121.

815 3. Drosou, C. G.; Krokida, M. K.; Biliaderis, C. G., Encapsulation of bioactive compounds 816 through electrospinning/electrospraying and spray drying: A comparative assessment of food817 related applications. Drying technology 2017, 35 (2), 139-162.

818 4. Singh, A.; Van den Mooter, G., Spray drying formulation of amorphous solid dispersions. 819 dvanced drug delivery reviews 2016, 100, 27-50.

$820 \quad 5 . \quad$ Broadhead, J.; Edmond Rouan, S.; Rhodes, C., The spray drying of pharmaceuticals. Drug 821 development industrial pharmacy 1992, 18 (11-12), 1169-1206.

822 6. Dugas, V.; Broutin, J.; Souteyrand, E., Droplet evaporation study applied to DNA chip 823 manufacturing. Langmuir 2005, 21 (20), 9130-9136.

824 7. Shariatnia, S.; Veldanda, A.; Obeidat, S.; Jarrahbashi, D.; Asadi, A., Atomization of 825 cellulose nanocrystals aqueous suspensions in fused deposition modeling: A scalable technique 826 to improve the strength of 3D printed polymers. Composites Part B: Engineering 2019, 177, 827107291.

828 8. Kuznetsov, I.; Greenfield, M.; Mehta, Y.; Merchan-Merchan, W.; Salkar, G.; Saveliev, A., Increasing the solar cell power output by coating with transition metal-oxide nanorods. Applied energy 2011, 88 (11), 4218-4221.

831 9. Krebs, F. C., Fabrication and processing of polymer solar cells: A review of printing and coating techniques. Solar energy materials solar cells 2009, 93 (4), 394-412. 10. Girotto, C.; Rand, B. P.; Genoe, J.; Heremans, P., Exploring spray coating as a deposition technique for the fabrication of solution-processed solar cells. Solar energy materials solar cells 2009, 93 (4), 454-458. of aerosol-jet printed electronics by using silver nanoparticles ink with carbon nanotubes. Microelectronic Engineering 2012, 96, 71-75. 3D structures with Aerosol Jet technology, 2012 Future of Instrumentation International Workshop (FIIW) Proceedings, IEEE: 2012; pp 1-4. nanocoating: the effects on pool boiling heat transfer and nucleation mechanism. International Journal of Heat and Mass Transfer 2009, 52 (23-24), 5459-5471. industry: part 1-hardware in steel making to the continuous annealing process. Journal of thermal spray technology 2010, 19 (6), 1267-1276. of material systems and future perspectives. Surface Engineering 2014, 30 (6), 369-395.

16. Barbezat, G., Advanced thermal spray technology and coating for lightweight engine blocks for the automotive industry. Surface Coatings Technology 2005, 200 (5-6), 1990-1993. 
852 17. Fauchais, P. L.; Heberlein, J. V.; Boulos, M. I., Wire arc spraying. In Thermal Spray 853 Fundamentals, Springer: 2014; pp 577-629.

854 18. Gedzevicius, I.; Valiulis, A., Analysis of wire arc spraying process variables on coatings properties. Journal of Materials Processing Technology 2006, 175 (1-3), 206-211.

19. Calvert, P. J. C. o. m., Inkjet printing for materials and devices. Chemistry of materials 2001, 13 (10), 3299-3305.

858 20. Dinh, N. T.; Sowade, E.; Blaudeck, T.; Hermann, S.; Rodriguez, R. D.; Zahn, D. R.; Schulz, 859 S. E.; Baumann, R. R.; Kanoun, O., High-resolution inkjet printing of conductive carbon nanotube twin lines utilizing evaporation-driven self-assembly. Carbon 2016, 96, 382-393. conductor based on the coffee ring effect. Journal of Materials Chemistry C 2014, 2 (45), 95879591.

22. Bugakova, D.; Slabov, V.; Sergeeva, E.; Zhukov, M.; Vinogradov, A., Comprehensive characterization of TiO2 inks and their application for inkjet printing of microstructures. Colloids Surfaces A: Physicochemical Engineering Aspects 2019, 124146. improved spray process to deposit novel coatings. Surface Coatings Technology 2008, 202 (18), 4369-4373.

24. Kuroda, S.; Kawakita, J.; Watanabe, M.; Kim, K.; Molak, R.; Katanoda, H., Current status and future prospects of warm spray technology. In Future Development of Thermal Spray Coatings, Elsevier: 2015; pp 163-206. 25. Heimann, R. B., Plasma-spray coating. Principles Applications 1996, 2.

26. Cao, X.; Vassen, R.; Schwartz, S.; Jungen, W.; Tietz, F.; Stöever, D., Spray-drying of ceramics for plasma-spray coating. Journal of the European Ceramic Society 2000, 20 (14-15), $876 \quad 2433-2439$.

877 27. Ke, D.; Vu, A. A.; Bandyopadhyay, A.; Bose, S., Compositionally graded doped hydroxyapatite coating on titanium using laser and plasma spray deposition for bone implants. Acta biomaterialia 2019, 84, 414-423.

28. Watanabe, T.; Sato, T.; Nezu, A., Electrode phenomena investigation of wire arc spraying for preparation of Ti-Al intermetallic compounds. Thin Solid Films 2002, 407 (1-2), 98-103. 29. Pawlowski, L., The science and engineering of thermal spray coatings. John Wiley \& Sons: 2008.

30. Fauchais, P.; Vardelle, M.; Vardelle, A.; Goutier, S., What do we know, what are the current limitations of suspension plasma spraying? Journal of Thermal Spray Technology 2015, 24 (7), 1120-1129.

31. Davis, J. R., Handbook of thermal spray technology. ASM international: 2004.

32. Fotovvati, B.; Namdari, N.; Dehghanghadikolaei, A., On coating techniques for surface protection: a review. Journal of Manufacturing Materials Processing 2019, 3 (1), 28.

33. Le, H. P., Progress and trends in ink-jet printing technology. ournal of Imaging Science Technology 1998, 42 (1), 49-62.

34. Carter, J. C.; Alvis, R. M.; Brown, S. B.; Langry, K. C.; Wilson, T. S.; McBride, M. T.; Myrick, M.; Cox, W. R.; Grove, M. E.; Colston, B. W., Fabricating optical fiber imaging sensors using inkjet printing technology: A pH sensor proof-of-concept. Biosensors and Bioelectronics 2006, 21 (7), 1359-1364. 
35. Chang, S. C.; Liu, J.; Bharathan, J.; Yang, Y.; Onohara, J.; Kido, J., Multicolor organic lightemitting diodes processed by hybrid inkjet printing. Advanced Materials 1999, 11 (9), 734-737. 36. Han, S.-Y.; Lee, D.-H.; Herman, G. S.; Chang, C.-H., Inkjet-printed high mobility transparent-oxide semiconductors. Journal of Display Technology 2009, 5 (12), 520-524. 37. Haverinen, H. M.; Myllylä, R. A.; Jabbour, G. E., Inkjet printing of light emitting quantum dots. Applied Physics Letters 2009, 94 (7), 073108.

38. Haverinen, H. M.; Myllyla, R. A.; Jabbour, G. E., Inkjet printed RGB quantum dot-hybrid LED. Journal of display technology 2010, 6 (3), 87-89.

39. Kawase, T.; Shimoda, T.; Newsome, C.; Sirringhaus, H.; Friend, R. H., Inkjet printing of polymer thin film transistors. Thin solid films 2003, 438, 279-287.

40. Hedges, M.; Marin, A. B. In 3D Aerosol jet printing-Adding electronics functionality to $R P / R M, D D M C 2012$ conference, 2012; pp 14-15.3.

41. Ebert, J.; Özkol, E.; Zeichner, A.; Uibel, K.; Weiss, Ö.; Koops, U.; Telle, R.; Fischer, H., Direct inkjet printing of dental prostheses made of zirconia. Journal of dental research 2009, 88 (7), 673-676.

42. Cui, X.; Boland, T.; DD'Lima, D.; K Lotz, M., Thermal inkjet printing in tissue engineering and regenerative medicine. Recent patents on drug delivery formulation 2012, 6 (2), 149-155. 43. Boland, T.; Xu, T.; Damon, B.; Cui, X., Application of inkjet printing to tissue engineering. Biotechnology Journal: Healthcare Nutrition Technology 2006, 1 (9), 910-917.

44. Cummins, G.; Desmulliez, M. P., Inkjet printing of conductive materials: a review. Circuit world 2012.

45. Derby, B., Inkjet printing ceramics: From drops to solid. Journal of the European Ceramic Society 2011, 31 (14), 2543-2550. nanoparticles by chemically controlled reduction for applications of inkjet-printed electronics.

922 47. Magdassi, S., In The Chemistry of Inkjet Inks; Magdassi, S., Ed. World Scientific Publishing 923 Co. Pte. Ltd.: Hackensack, NJ: 2010.

924 48. Deegan, R. D.; Bakajin, O.; Dupont, T. F.; Huber, G.; Nagel, S. R.; Witten, T. A. J. N., 925 Capillary flow as the cause of ring stains from dried liquid drops. Nature 1997, 389 (6653), 827.

926 49. Yunker, P. J.; Still, T.; Lohr, M. A.; Yodh, A., Suppression of the coffee-ring effect by shapedependent capillary interactions. Nature 2011, 476 (7360), 308-311.

50. Anyfantakis, M.; Geng, Z.; Morel, M.; Rudiuk, S.; Baigl, D. J. L., Modulation of the coffeering effect in particle/surfactant mixtures: the importance of particle-interface interactions. Langmuir 2015, 31 (14), 4113-4120.

51. Nguyen, V. X.; Stebe, K. J., Patterning of small particles by a surfactant-enhanced Marangoni-Bénard instability. Physical Review Letters 2002, 88 (16), 164501.

52. Seo, C.; Jang, D.; Chae, J.; Shin, S., Altering the coffee-ring effect by adding a surfactantlike viscous polymer solution. Scientific reports 2017, 7 (1), 500.

53. Dicuangco, M.; Dash, S.; Weibel, J. A.; Garimella, S. V., Effect of superhydrophobic surface morphology on evaporative deposition patterns. Applied Physics Letters 2014, 104 (20), 201604. B., Avoiding coffee ring structure based on hydrophobic silicon pillar arrays during single-drop evaporation. Soft Matter 2012, 8 (40), 10448-10456. 
55. Mampallil, D.; Eral, H.; Van Den Ende, D.; Mugele, F., Control of evaporating complex fluids through electrowetting. Soft Matter 2012, 8 (41), 10614-10617.

942 56. Mampallil, D.; Reboud, J.; Wilson, R.; Wylie, D.; Klug, D. R.; Cooper, J. M., Acoustic suppression of the coffee-ring effect. Soft matter 2015, 11 (36), 7207-7213.

944 57. Mampallil, D.; Eral, H. B., A review on suppression and utilization of the coffee-ring effect. Advances in colloid interface science 2018, 252, 38-54. sprays, Future, opportunities and challenges of inkjet technologies. Atomization and sprays 2013, 23 (6).

59. Seifert, T.; Sowade, E.; Roscher, F.; Wiemer, M.; Gessner, T.; Baumann, R. R., Additive manufacturing technologies compared: morphology of deposits of silver ink using inkjet and aerosol jet printing. Industrial Engineering Chemistry Research 2015, 54 (2), 769-779. 60. Mooney, J. B.; Radding, S. B., Spray pyrolysis processing. Annual review of materials science 1982, 12 (1), 81-101.

61. Vehring, R.; Foss, W. R.; Lechuga-Ballesteros, D., Particle formation in spray drying. ournal of Aerosol Science 2007, 38 (7), 728-746.

62. Sollohub, K.; Cal, K., Spray drying technique: II. Current applications in pharmaceutical technology. Journal of pharmaceutical sciences 2010, 99 (2), 587-597.

63. Qi, S.; Craig, D., Recent developments in micro-and nanofabrication techniques for the preparation of amorphous pharmaceutical dosage forms. Advanced Drug Delivery Reviews 2016, 100, 67-84.

64. Raula, J.; Eerikäinen, H.; Kauppinen, E. I., Influence of the solvent composition on the aerosol synthesis of pharmaceutical polymer nanoparticles. International journal of pharmaceutics 2004, 284 (1-2), 13-21. 65. Haque, E.; Shariatnia, S.; Jeong, T.-J.; Jarrahbashi, D.; Asadi, A.; Harris, T.; Moon, R. J.; Kalaitzidou, K., Scalable coating methods for enhancing glass fiber-epoxy interactions with cellulose nanocrystals. Cellulose 2021, 1-16.

66. Wei, Y.; Huang, Y.-H.; Cheng, K.-C.; Song, Y.-L., Investigations of the Influences of Processing Conditions on the Properties of Spray Dried Chitosan-Tripolyphosphate Particles loaded with theophylline. Scientific Reports 2020, 10 (1), 1-12.

973 68. Lu, S.; Zheng, J.; Cardenas, J. A.; Williams, N. X.; Lin, Y.-C.; Franklin, A. D., Uniform and 67. Wilkinson, N.; Smith, M.; Kay, R.; Harris, R., A review of aerosol jet printing-a nontraditional hybrid process for micro-manufacturing. The International Journal of Advanced Manufacturing Technology 2019, 105 (11), 4599-4619.

978 70. Mette, A.; Richter, P.; Hörteis, M.; Glunz, S., Metal aerosol jet printing for solar cell Stable Aerosol Jet Printing of Carbon Nanotube Thin-Film Transistors by Ink Temperature Control. ACS Applied Materials Interfaces 2020, 12 (38), 43083-43089.

69. Secor, E. B., Principles of aerosol jet printing. Flexible and Printed Electronics 2018, 3 (3), 035002.

982

71. Azarova, N. A.; Owen, J. W.; McLellan, C. A.; Grimminger, M. A.; Chapman, E. K.; Anthony, J. E.; Jurchescu, O. D., Fabrication of organic thin-film transistors by spray-deposition for low-cost, large-area electronics. Organic Electronics 2010, 11 (12), 1960-1965. 
72. Sarobol, P.; Cook, A.; Clem, P. G.; Keicher, D.; Hirschfeld, D.; Hall, A. C.; Bell, N. S., Additive manufacturing of hybrid circuits. Annual Review of Materials Research 2016, 46, 41-62. 73. Jabari, E.; Toyserkani, E. J. C., Micro-scale aerosol-jet printing of graphene interconnects. Carbon 2015, 91, 321-329.

74. Goth, C.; Putzo, S.; Franke, J. In Aerosol Jet printing on rapid prototyping materials for fine pitch electronic applications, 2011 IEEE 61st Electronic Components and Technology Conference (ECTC), IEEE: 2011; pp 1211-1216.

75. Mahajan, A.; Frisbie, C. D.; Francis, L. F., Optimization of aerosol jet printing for highresolution, high-aspect ratio silver lines. ACS applied materials interfaces 2013, 5 (11), 4856-4864. 76. Reverchon, E., Supercritical-assisted atomization to produce micro-and/or nanoparticles of controlled size and distribution. Industrial engineering \& chemistry research 2002, 41 (10), 2405-2411.

77. Shariati, A.; Peters, C. J., Recent developments in particle design using supercritical fluids. Current Opinion in Solid State Materials Science 2003, 7 (4-5), 371-383.

78. Tom, J. W.; Debenedetti, P. G., Particle formation with supercritical fluids-a review. Journal of Aerosol Science 1991, 22 (5), 555-584.

79. Reverchon, E., Process for the production of micro and/or nano particles. Google Patents: 2007.

80. Diamond, L. W.; Akinfiev, N. N., Solubility of $\mathrm{CO} 2$ in water from- 1.5 to $100 \mathrm{C}$ and from 0.1 to $100 \mathrm{MPa}$ : evaluation of literature data and thermodynamic modelling. Fluid phase equilibria 2003, 208 (1-2), 265-290.

81. Aguiar-Ricardo, A., Building dry powder formulations using supercritical $\mathrm{CO} 2$ spray drying. Current Opinion in Green Sustainable Chemistry 2017, 5, 12-16.

82. Nunes, A. V.; Duarte, C. M., Dense CO2 as a solute, co-solute or co-solvent in particle formation processes: a review. Materials 2011, 4 (11), 2017-2041.

83. Costa, C.; Casimiro, T.; Aguiar-Ricardo, A., Optimization of supercritical CO2-assisted atomization: Phase behavior and design of experiments. Journal of Chemical Engineering Data 2018, 63 (4), 885-896.

84. Della Porta, G.; De Vittori, C.; Reverchon, E., Supercritical assisted atomization: a novel technology for microparticles preparation of an asthma-controlling drug. Aaps Pharmscitech 2005, 6 (3), E421-E428.

85. Shariatnia, S.; Asadi, A.; Jarrahbashi, D., Experimental analysis of supercritical-assisted atomization. Physics of Fluids 2021, 33 (1), 013314.

86. Palaganas, N. B.; Mangadlao, J. D.; de Leon, A. C. C.; Palaganas, J. O.; Pangilinan, K. D.; Lee, Y. J.; Advincula, R. C., 3D printing of photocurable cellulose nanocrystal composite for fabrication of complex architectures via stereolithography. ACS applied materials interfaces 2017, 9 (39), 34314-34324.

87. Tang, J.; Sisler, J.; Grishkewich, N.; Tam, K. C., Functionalization of cellulose nanocrystals for advanced applications. Journal of colloid interface science 2017, 494, 397-409.

88. Shariatnia, S.; Kumar, A. V.; Kaynan, O.; Asadi, A., Hybrid Cellulose Nanocrystals-Bonded Carbon Nanotubes/Carbon Fiber Polymer Composites for Structural Applications. ACS Applied Nano Materials 2020.

89. Roman, M.; Dong, S.; Hirani, A.; Lee, Y. W., Cellulose nanocrystals for drug delivery. ACS Publications: 2009. 
1027

1028

1029

1030

1031

1032

1033

1034

1035

1036

1037

1038

1039

1040

1041

1042

1043

1044

1045

1046

1047

1048

1049

1050

1051

1052

1053

1054

1055

1056

1057

1058

1059

1060

1061

1062

1063

1064

1065

1066

1067

1068

1069

1070

90. Grishkewich, N.; Mohammed, N.; Tang, J.; Tam, K. C., Recent advances in the application of cellulose nanocrystals. Current Opinion in Colloid Interface Science 2017, 29, 32-45.

91. Mariano, M.; El Kissi, N.; Dufresne, A., Cellulose nanocrystals and related nanocomposites: review of some properties and challenges. Journal of Polymer Science Part B: Polymer Physics 2014, 52 (12), 791-806.

92. Moon, R. J.; Martini, A.; Nairn, J.; Simonsen, J.; Youngblood, J., Cellulose nanomaterials review: structure, properties and nanocomposites. Chemical Society Reviews 2011, 40 (7), 39413994.

93. Parker, R. M.; Frka-Petesic, B.; Guidetti, G.; Kamita, G.; Consani, G.; Abell, C.; Vignolini, S., Hierarchical self-assembly of cellulose nanocrystals in a confined geometry. ACS nano 2016, 10 (9), 8443-8449.

94. Mu, X.; Gray, D. G., Droplets of cellulose nanocrystal suspensions on drying give iridescent 3-D "coffee-stain" rings. Cellulose 2015, 22 (2), 1103-1107.

95. Parker, R. M.; Guidetti, G.; Williams, C. A.; Zhao, T.; Narkevicius, A.; Vignolini, S.; FrkaPetesic, B., The Self-Assembly of Cellulose Nanocrystals: Hierarchical Design of Visual Appearance. Advanced Materials 2018, 30 (19), 1704477.

96. Shopsowitz, K. E.; Qi, H.; Hamad, W. Y.; MacLachlan, M. J., Free-standing mesoporous silica films with tunable chiral nematic structures. Nature 2010, 468 (7322), 422-425.

97. Gu, M.; Jiang, C.; Liu, D.; Prempeh, N.; Smalyukh, I. I., Cellulose nanocrystal/poly (ethylene glycol) composite as an iridescent coating on polymer substrates: structure-color and interface adhesion. ACS applied materials interfaces 2016, 8 (47), 32565-32573.

98. Andrews, S.; Nover, D.; Reuter, J.; Schladow, S., Limitations of laser diffraction for measuring fine particles in oligotrophic systems: Pitfalls and potential solutions. Water Resources Research 2011, 47 (5).

99. Weller, H. G.; Tabor, G.; Jasak, H.; Fureby, C., A tensorial approach to computational continuum mechanics using object-oriented techniques. Computers in physics 1998, 12 (6), 620631.

100. Tsang, C.-W.; Trujillo, M. F.; Rutland, C. J., Large-eddy simulation of shear flows and highspeed vaporizing liquid fuel sprays. Computers and Fluids 2014, 105, 262-279.

101. Mishra, R.; Rutland, C. Evaluating Surface Film Models for Multi-Dimensional Modeling of Spray-Wall Interaction; 0148-7191; SAE Technical Paper: 2019.

102. Stanton, D. W.; Rutland, C. J., Modeling fuel film formation and wall interaction in diesel engines. SAE transactions 1996, 808-824.

103. Markt, D. P.; Torelli, R.; Pathak, A.; Raessi, M.; Som, S.; Scarcelli, R.; Lee, S.-Y.; Naber, J. Using a DNS framework to test a splashed mass sub-model for Lagrangian spray simulations; 0148-7191; SAE Technical Paper: 2018.

104. Reitz, R. D., Modeling Atomization Processes in High-Pressure Vaporizing Sprays. Atomization and Spray Technology 1987, Vol 3, 309-337.

105. Zuo B., G. A. M., Rutland C. J., Studies of Superheated Fuel Spray Structures and Vaporization in GDI Engines. International Journal of Engine Research 2000, Vol. 1(4), 321-336.

106. Ranz , W. E., Marshall , W.R, Evaporation from drops. Chem. Eng. Prog 1952, 48, 141-146. 107. Jarrahbashi, D.; Kim, S.; Genzale, C. L., Simulation of Combustion Recession After End-ofInjection at Diesel Engine Conditions. Journal of Engineering for Gas Turbines and Power 2017, 139 (10), 102804-102804-8. 
1071 108. Jarrahbashi, D.; Kim, S.; Knox, B. W.; Genzale, C. L., Computational analysis of end-of1072 injection transients and combustion recession. International Journal of Engine Research 2017, 18 1073 (10), 1088-1110.

1074 109. Stanton D., R. C., Modeling Fuel Film Formation and Wall Interaction in Diesel Engines. 1075 SAE Technical Paper 1996, (960628), 10.4271/960628.

1076 110. W., W., A statistical distribution function of wide applicability. J Appl Mech 1951, 18, 2931077297.

1078 111. Jarrahbashi, D.; Sirignano, W. A., Vorticity dynamics for transient high-pressure liquid 1079 injection. Physics of Fluids 2014, 26 (10), 101304.

1080 112. Jarrahbashi, D.; Sirignano, W. A.; Popov, P. P.; Hussain, F., Early spray development at 1081 1082 high gas density: hole, ligament and bridge formations. Journal of Fluid Mechanics 2016, 792, 186-231.

1084

1085 113. Diamond, L. W.; Akinfiev, N. N., Solubility of CO2 in water from -1.5 to $100{ }^{\circ} \mathrm{C}$ and from 0.1 to $100 \mathrm{MPa}$ : evaluation of literature data and thermodynamic modelling. Fluid Phase Equilibria 2003, 208 (1-2), 265-290.

1086 114. Bachu, S.; Bennion, D. B., Interfacial tension between $\mathrm{CO} 2$, freshwater, and brine in the 1087 1088 range of pressure from (2 to 27) $\mathrm{MPa}$, temperature from (20 to 125) $\mathrm{C}$, and water salinity from (0 to 334 000) mg. L- 1. Journal of Chemical Engineering Data 2009, 54 (3), 765-775.

1089 115. Tewes, F.; Boury, F., Formation and Rheological Properties of the Supercritical CO21090 Water Pure Interface. The Journal of Physical Chemistry B 2005, 109 (9), 3990-3997. 116. Bouse, L.; Kirk, I.; Bode, L., Effect of spray mixture on droplet size. Transactions of the ASAE 1990, 33 (3), 783-0788.

117. Dayal, P.; Shaik, M. S.; Singh, M., Evaluation of different parameters that affect dropletsize distribution from nasal sprays using the Malvern Spraytec ${ }^{\circledR}$. Journal of pharmaceutical sciences 2004, 93 (7), 1725-1742.

118. Govor, L.; Reiter, G.; Bauer, G.; Parisi, J., Nanoparticle ring formation in evaporating micron-size droplets. Applied physics letters 2004, 84 (23), 4774-4776.

1098 119. Lu, G.; Hu, H.; Duan, Y.; Sun, Y., Wetting kinetics of water nano-droplet containing nonsurfactant nanoparticles: A molecular dynamics study. Applied Physics Letters 2013, 103 (25), 253104.

120. Vehring, R., Pharmaceutical particle engineering via spray drying. Pharmaceutical 1102 research 2008, 25 (5), 999-1022.

1103 121. Wei, Y., Effect of particles on evaporation of droplet containing particles. 2015.

1104 122. Mampallil, D.; Eral, H. B., A review on suppression and utilization of the coffee-ring effect. 1105 Adv Colloid Interface Sci 2018, 252, 38-54.

1106 123. Hu, H.; Larson, R. G., Evaporation of a sessile droplet on a substrate. The Journal of 1107 Physical Chemistry B 2002, 106 (6), 1334-1344.

124. Nguyen, T. A.; Nguyen, A. V., Increased evaporation kinetics of sessile droplets by using nanoparticles. Langmuir 2012, 28 (49), 16725-16728. 125. Hu, H.; Larson, R. G., Analysis of the microfluid flow in an evaporating sessile droplet. Langmuir 2005, 21 (9), 3963-3971.

1112 126. Weast, R.; Astle, M. J. C., Boca Raton, Fla, CRC Handbook of chemistry and physics 62nd 1113 ed. 1981. 
1114 127. Van Rie, J.; Schütz, C.; Gençer, A.; Lombardo, S.; Gasser, U.; Kumar, S.; Salazar-Alvarez, 1115 G. n.; Kang, K.; Thielemans, W., Anisotropic diffusion and phase behavior of cellulose nanocrystal 1116 suspensions. Langmuir 2019, 35 (6), 2289-2302. 